\title{
Improving maternal health services through social accountability interventions in Nepal: An analytical review of existing literature
}

Adweeti Nepal ( $\nabla$ anepal7@gmail.com )

Save the Children

\section{Santa Kumar Dangol}

CARE-Nepal

Anke van der Kwaak

Royal Tropical Institute (KIT)

Research article

Keywords: Social accountability, community participation, maternal health services, health system, responsiveness, quality of care

Posted Date: September 19th, 2019

DOI: https://doi.org/10.21203/rs.2.14589/v1

License: (c) (i) This work is licensed under a Creative Commons Attribution 4.0 International License. Read Full License

Version of Record: A version of this preprint was published at Public Health Reviews on December 1st, 2020. See the published version at https://doi.org/10.1186/s40985-020-00147-0. 


\section{Abstract}

Background: The persistent equity and quality gap in maternal health services in Nepal has resulted in poor maternal health outcomes. The Government of Nepal has emphasized on responsive and accountable maternal health services since 2005 , while social accountability interventions have been commenced as a strategical approach. This review is an attempt to critically explore the social accountability interventions in maternal health services in Nepal and its outcomes by analyzing existing evidence to contribute informed policy.

Methods: A literature review and desk study were done between December 2018 to May 2019. An adapted framework of social accountability by Lodenstein et al. 2013 was used for critical analysis and synthesis of the existing literature from Nepal and other low- and middle-income countries (LMICs). The literature was searched and extracted from the search engines i.e. google and google scholar using keywords. The searched includes both published and grey literature.

Results: The review found different social accountability interventions initiated by the government and external development partners in maternal health services in Nepal. The evidence from Nepal and other LMICs showed that the social accountability interventions improve the quality of maternal health services through improving health system responsiveness, enhancing community ownership, addressing inequalities and enabling the community to influence the policy decision-making process. The strong gender norms, caste-hierarchy system, socio-political and economic context and weak enforceability mechanism in the health system are major contextual factors influencing community engagement in social accountability interventions in Nepal.

Conclusions: The evidence show that social accountability interventions have the potential to improve the quality of maternal health services in Nepal. Critical factors of successful outcomes in maternal health services include quality implementation of the interventions. Similarly, continuous effort is needed from policymaker to strengthen monitoring and regulatory mechanism of the health system and decentralization, improve access to the information and establishment of proper channels to capture complaints and feedback from the community to ensure the effectiveness of the interventions for the long run. Furthermore, research is needed to evaluate the impact of the existing social accountability interventions in the reduction of maternal mortality in Nepal.

\section{Background}

The world has made remarkable progress in the reduction of maternal mortality across the Millennium Development Goal (MDG) regions between 1990 and 2015. However, variation in the magnitude of maternal mortality has been evident in between and among the regions. It is estimated that every day, around 830 women die from the pregnancy-or-child-birth related complications globally. Among all $99 \%$ of deaths occur in the developing countries while two-thirds of deaths occur in Sub-Saharan Africa followed by South-Asia, meanwhile, they are preventable [1]. 
In the last two decades, Nepal has made a significant effort to improve the maternal health status. The Government of Nepal (GoN) launched the Safe Motherhood programme in 1997 with the aim of improving maternal and neonatal outcomes [2]. Subsequently, under the programme, the government has launched various policies, programmes and strategies. In 2005, the government introduced a maternity scheme which is named as 'Aama[i] programme' to address the financial barriers and improve access to maternal health services. The scheme includes free institutional delivery, the incentive for the recommended 4 ANC visits and transportation incentive to women for institutional delivery [3]. In 2006 the Skilled Birth Attendants (SBA) policy was introduced as a supplement of safe motherhood policy [4]. The policy has emphasized on institutional delivery and SBA at each birth. As a result, institutional delivery is widely promoted which led to nationwide expansion of birthing centers. Since then, there is a considerable increment in the coverage of institutional delivery from $8 \%$ in 1996 to $57 \%$ in 2016 . However, expansion of birthing centers has not ensured the quality of care (QoC) at service delivery point up as government standard [5]. Despite all efforts, the country is still facing challenges to reduce maternal mortality ratio (MMR) as per national and global target. As per as Nepal Health Demographic Health Survey (NDHS) 2016, the MMR is 239 per 100,000 live births [6].

The main cause of maternal mortality in Nepal is associated with the three delays i.e. delay in seeking, reaching and receiving care. Persistent equity and quality gap in maternal health services are the underlying causes for the slow and steady progress in maternal health outcomes in Nepal $[3,7]$. The NDHS 2016 has shown that the access and utilization of maternal health services are still primarily low among less-educated women, women of lowest wealth quintile and hard-to-reach area which outlines equity gap in the maternal health services in the country [6]. In Nepal, 95\% of birthing centers have not satisfied the requirements of Safe motherhood programme. The infection prevention practices are considerably low among the staff at birthing centers. Only half of the nursing staff of birthing centers are certified SBA [5]. The health system-related factors such as cleanliness, hygiene, poor counseling, and audio-visual privacy, lack of essential drugs and supplies, staff absenteeism and their attitude are major reasons behind dissatisfaction to maternal health services among the maternity clients [8]. Similarly, lack of confidence is a reason for underutilization of primary level of care which has resulted in overcrowding at the maternity unit in referral hospitals that has further challenged the referral hospitals to satisfy the increased demand of care [9]. Eventually, the weak monitoring and enforceability mechanism and low responsive health system are evident as factors associated with quality and equity gap in maternal health services in Nepal [7]. The evidence, hence, indicate that only emphasizing on accessibility to the essential maternal health services neither ensures the service utilization nor optimal maternal health outcomes. Researchers suggested that it is essential to go beyond maximizing essential interventions to accelerate the progress in maternal health outcomes and need to invest for the quality maternal health services through accountable health system particularly in developing context $[10,11]$.

Social accountability refers to an approach that enables the citizens to make service provider and policymakers responsible and answerable for their acts [12]. It has been proven as an effective strategy to aggregate the voice of disadvantaged and marginalized people, enhance citizen-service provider 
relationships and improve state/service provider responsiveness toward effective and quality service delivery in developing context [13-15]. In the health system, it improves health service provider and policymaker responsiveness which results in increased service utilization and reduces disease prevalence in this case maternal morbidity and mortality $[15,16]$. Meanwhile, improved uptake of maternal health services is considered as an important effort to reduce avoidable maternal death in the LMICs $[10,11]$.

The Ministry of Health and Population (MoHP), Nepal has emphasized on the governance and accountability in the health system to improve the quality of care at a point-of-delivery where Nepal Health Sector Strategy (NHSS) 2015-2020 is a major guiding document for it. The strategy has envisioned for access to quality health services primarily focusing poor and marginalized population through accountability interventions [7]. Apart from this, different development organizations are providing technical support to the MoHP for the interventions. However, limited evidence is available on social accountability interventions and their outcome in maternal health services in the context of Nepal. Therefore, this analysis is initiated to inform policymaker and health service provider working to improve maternal health services. For the comprehensive analysis, the adapted conceptual framework of Lodenstein et al. 2013 [17] was used. As the review is solely focused on maternal health services, the original framework, therefore, has been revised to conduct a comprehensive analysis of the findings linking social accountability interventions and maternal health services in the context of Nepal.

[i] Aama refers mother in Nepali language

\section{Methods}

A thorough literature review from different LMICs including Nepal was done to explore the social accountability interventions and its outcome in maternal health services in Nepal. The review was done in December 2018-May 2019. Due to limited time and resources, a rapid literature and desk review was done to summarize the findings on social accountability interventions in maternal health services in the context of Nepal. The adapted framework of Lodenstein et al. 2013 was used to critically analyse and synthesize existing literature. The framework was chosen over the World bank accountability framework as the World Bank's model specifically focuses on the citizen-policymaker relationship and has not discussed the importance of the contextual factors. Therefore, the chosen framework has accommodated the limitation of World bank's model and found more relevant for this review.

\section{Fig 1.Conceptual framework on social accountability adapted from Lodenstein et al., 2013 [17].}

Originally, Lodenstein et al. 2013, has conceptualized the social accountability interventions as a citizendriven mechanism, where citizens voice their concern on the quality of services or/and service provider's and policymaker's performance. In return, the service provider and policymakers are asked to respond to 
those concerns [17]. Equally, citizen oversight the service provider's and policymaker's actions and decisions using accountability mechanism which result in improved responsiveness of service providers and policymakers. Improved responsiveness ultimately creates health and rights impact. The interventions, outcome, and impact are, however, influenced by different contextual factors [17].

Since World Health Organization (WHO) has recognized community engagement interventions as cornerstone to improving the quality of maternal and newborn care and Nepal has also adopted a community participation approach in its health system, we, therefore, have incorporated community engagement and community oversight as a central element of the social accountability interventions [3, 18]. In this case, the community engagement refers to the community voice or expression of concerns for the quality maternal health services without formal enforcement and community oversight include joint monitoring and evaluation of the maternal health services and health system. The interventions anticipated to improve health service provider's and policymaker's responsiveness toward delivering quality maternal health services. Improved responsiveness ultimately creates health and rights impact by reducing maternal mortality, promoting equity and good governance. Eventually, the interventions, outcomes, and impact are influenced by socio-cultural, political and economic and health system-related factors.

The main keywords related to conceptual framework i.e. 'Social accountability interventions', 'maternal health services', 'community participation', 'outcomes' and 'Nepal' were combined using Boolean operator terms 'OR' and 'AND' to narrow down the search and produce conclusive evidence on the interventions. Literature was searched and extracted via search engine Google and PubMed database. For the National reports and data, we visited authentic websites of Government of Nepal (GoN), different development agencies and organizations websites which include MoHP Nepal, Department of Health Services (DoHS) Nepal, Ministry of Federal Affairs and Local Development (MoFALD), WHO, World Bank and CARE Nepal. Additionally, snowball approached used to access references mentioned in key review papers. While there was limited evidence on the outcomes of social accountability interventions in Nepal, we have included evidence from other LMICs having similar maternal health and socio-economic context.

Aligning with the Local Self-Governance Act 1999, the MoHP implemented decentralization in health in 2000, we, therefore, set 2000 as the lower limit for literature search. All published and unpublished (grey) and open-access literature between 2000 and May 2019 was included in this review. Some policy documents that are published in the Nepali language have been translated into English and included in the review because of the information relevancy. Researches focus on other approaches and interventions to improve maternal health services were excluded from this paper. For the national data, we used NDHS 2016 and Annual report of the DoHS as a reference. Altogether 479 free full-text articles from January 2000 to May 2019 were identified from the PubMed with the combination of keywords.

Additional 46 articles were identified from other sources, google and Scopus and recommendation from academicians. Among the total 525 articles, 31 duplicate articles were removed. From the remaining 494 articles, 433 were removed as they did not match the title of the study, place of the study and study 
population from the list. At last 26 articles were removed as they did not have enough information and 35 articles were finally reviewed for the articles together with other reports and document. The article selection process is presented in Fig 2.

\section{Figure 2 Article selection process}

The result is presented following the elements of the conceptual framework. Furthermore, the conceptual framework is based on theoretical perspectives i.e. social accountability, health system responsiveness and quality of care which has been defined and presented in table 1.

\section{Table 1 Conceptual definition}




\begin{tabular}{|c|c|}
\hline & Definition \\
\hline $\begin{array}{l}\text { Social } \\
\text { accountability }\end{array}$ & $\begin{array}{l}\text { Social accountability is termed as an approach that enhances accountability through } \\
\text { civic engagement. The civic includes citizens and/or civil societies who directly or } \\
\text { indirectly hold service providers accountable for their actions. This approach is } \\
\text { commonly demand-driven; however, it can be supported by the state as well through } \\
\text { the formal mechanism. It is also known as participatory approaches that involve the } \\
\text { citizen in policymaking, budget and expenditure tracking and monitoring and } \\
\text { evaluation of the service delivery. In the health system, it ensures the quality of care } \\
\text { by empowering citizen, protecting their rights, preventing corruption and improving } \\
\text { governance }[13,19] \text {. }\end{array}$ \\
\hline $\begin{array}{l}\text { Social } \\
\text { accountability } \\
\text { interventions }\end{array}$ & $\begin{array}{l}\text { In this paper, social accountability interventions refer to the approaches, processes, } \\
\text { tools, interventions, initiatives that involve community engagement and oversight to } \\
\text { enhance health system responsiveness. This definition is adopted from the concept } \\
\text { presented by Lodenstein et al. } 2013 \text {. }\end{array}$ \\
\hline $\begin{array}{l}\text { Health system } \\
\text { responsiveness }\end{array}$ & $\begin{array}{l}\text { Health system responsiveness is termed as an ability of health system (both health } \\
\text { services and policymakers) to respond valid expectations of service users and to } \\
\text { protecting their rights to get adequate and timely care [20]. In this paper, the health } \\
\text { system responsiveness refers to the health service provider's and policymaker's } \\
\text { responses toward community voice and demand regarding quality maternal health } \\
\text { services. The responses include a tendency to implement change in their behaviour } \\
\text { and attitude, decision-making and management structure for quality services at the } \\
\text { point-of-service-delivery which is adapted from Lodenstein et al. } 2017 \text { [15]. }\end{array}$ \\
\hline
\end{tabular}




\begin{tabular}{|l}
\hline Definition \\
\hline Quality of Care \\
The QoC in maternal health services involves proper use of effective clinical and non- \\
clinical interventions, strengthen health infrastructure and optimum skill and \\
attitudes of health service providers. Improved QoC results in women and service \\
provider satisfaction and produces better maternal health outcomes [10, 21]. \\
Furthermore, the perception of women's, their family and community about the \\
available maternal health services influence their health-seeking behaviour. Therefore, \\
community engagement is the key to improve the quality of maternal health services \\
[10, 11, 18]. \\
In this paper, QoC in maternal health services is defined on the basis of a benchmark \\
set by the birthing centres assessment 2014 [5] conducted by MoHP, Nepal. The QoC \\
indicators in maternal health services include attitude and behaviour of health service \\
providers, provision of basic services, availability of essential medicines, necessary \\
equipment and human resources in maternal health services.
\end{tabular}

\section{Results}

\section{Social accountability interventions in maternal health services in Nepal}

\section{Community engagement}

In Nepal, it is found that different social accountability tools have been used and tested either by government or development partners to ensure community engagement in social accountability interventions in maternal health services. The common tools used in maternal health services are described below.

\section{Social Audit}

The social audit has been initiated by the GoN since 2009 to ensure the quality implementation of Aama program [22, 23]. The main aim of this initiation is to increase women's and community awareness, promote transparency in the decision process of health facility, make the health workers and decisionmakers accountable and responsive for quality maternal health services, set a culture of demand for 
information from the health facility as well as strengthen mutual accountability between service providers and users [23].

The programme has been implemented through the local non-government organization (NGO) who are identified through a competitive process $[23,24]$. The NGOs facilitate the process of social audit where community and local stakeholders are invited to review the performance, identify existing problems and challenges of the health facility as well as develop an action plan for improving quality of services. The process takes 5-6 days to complete in one health facility in the initial stage. However, time implication is less in the follow-up programme [24].

The outcomes of social audit are supposed to be reviewed in district as well as regional level programme review meeting and provide necessary feedback to the concerned district and health facility on their action plan. However, the meetings usually limited to compiling the reports, rather than analysis of the results and quality of the process [22, 24]. Up to fiscal year 2016/17, the program has been scaled up to 70 districts out of 77 . The social audit was done in 1752 health facilities the up to 25 bed in the last fiscal year. The Government has a plan to scale up the program into all 77 districts by 2020 [7, 24].

\section{Maternal Perinatal Death Surveillance and Response (MPDSR)}

The WHO has recognized the Maternal Death Review (MDR) as a relevant accountability tool for improved quality of the maternal and neonatal health $(\mathrm{MNH})$ services which are based on the concept of the monitor-review-act cycle [25-27]. The process involves national-level monitoring and oversight of the results, multi-stakeholder analysis and action and all components of surveillance and responses systems [26].

The GoN firstly initiated the program in 1990 at the tertiary level hospital with the support of the WHO. Since then it has been scaled up at different levels of care at different phases with improvisation from the learnings of the programs. [27]. Recently, the government merged this MDR program with Maternal Perinatal Death Review (MPDR) program and developed a comprehensive surveillance system named 'Maternal Perinatal Death Surveillance and Response' (MPDSR). There are two types of MPDSR; facilitybased and community-based in Nepal $[3,27]$. It is a supply-side accountability intervention initiated to improve quality of maternal health services which is focused on routine identification and notification of maternal and perinatal deaths, determinants of death causes and use of the information to improve quality of care as well as management of the program to avoid future deaths [27]. The community-based intervention has been implemented in 6 districts whereas facility-based intervention has been expanded in 65 hospitals in 38 districts [3]. For the implementation, the committee is formed at district, hospital and local health facilities level. At the local level committee, there is a separate verbal autopsy and cause of death assignment team [3]. Fig 2 shows the process of the MPDSR.

Despite the effort, the implementation of the intervention is challenged by underreporting, delay reporting and incomplete reporting of death from peripheral health facilities, geographical difficulties and resources constraints [3]. 
Fig 3 Process of MPDSR at community and health facility level [3].

\section{- Community Score Card/Community Health Score Board}

Both community scorecard (CSC) and community health scoreboard (CHSB) are introduced at the same time in Nepal to promote health sector accountability. CSC is a tool designed to promote participation, transparency, and accountability among service providers, service users and decision-makers. The tool provides an opportunity for the community to evaluate the quality of services, express their dissatisfaction and voice health rights $[28,29]$. It is a process-oriented tool, where community people along with service providers and stakeholders monitor and evaluate health service against agreed indicators. With the support of indicators, quality of services, health facility performance, and health governance are monitored using define scale or score. At the end of the process, people along with service providers develop an action plan and prioritize the activities based on the given score for further improvement [29]. The tool was piloted in 16 health posts by the Government with support of World Bank in 2011 [28, 29] which was found effective for promoting direct feedback mechanism and efficient use of resources at a health facility. However, due to high implementation cost and lack of competent human resources for the facilitation of the process the government could not scale-up further $[22,28,29]$.

As a hybrid form of participatory rural appraisal (PRA), social audit and CSC, community health scoreboard (CHSB) has been introduced in maternal, neonatal and child health (MNCH) services with the support of CARE-Nepal $[22,30]$. The tool is based on the value and principle of community participation. The tool creates an environment for tri-party dialogue among service providers, beneficiaries and decision-makers which facilitates monitoring and performance of $\mathrm{MNCH}$ services [30, 31]. The dialogue is based on the indicators developed with the consultation with the district health office/district public health office (DHO/DPHO) [30]. Similar to the CSC, community people, service providers, and decisionmakers jointly discuss the $\mathrm{MNCH}$ issues and then provide mutually agreed scores on the performance indicators and develop action plans for further improvement. The action plans are reviewed semiannually following the same process. It provides an opportunity for immediate feedback to services provider and decision-makers and respond toward raised concerns [22, 30].

\section{Citizen Charter}

Citizen charter is an information board, displayed at all public service centres. It is a tool to ensure the constitutional right of the Nepali citizen to the information as well as express the government commitment for providing quality services in a transparent and accountable way [29]. The citizen charter includes the information about the availability of services, essential requirement to get services, name of the contact person, required time and name of the person to redress the grievances if any. The board also includes the information about the day, time and duration of services; fee/charges of services like labtest, $x$-ray; list of free health services and drugs; incentives information; terms and procedure; responsible 
health workers, etc. $[22,29]$. Since 2007 , GoN has made it mandatory to display it at clearly visible premises of all public office/facilities and this applied in the health sector as well [29,32].

The tool has been promoted in the health sector to ensure transparency, improve service providers' accountability, make the service users informed about the services and address the concern/grievances of citizen about the services [33], however, many gaps have been identified in posting information about the availability of essential drugs and services in the health facilities [33]. A report in social accountability in the health sector [22] stated that $29 \%$ of health facilities do not have citizen charter at their premises. And if the health facilities have, it hasn't been displaying properly [22]. Eventually, the weak enforceability mechanism in the health sector is one of the reason for it $[22,33]$.

\section{Grievance/Complaint handling tool}

The GoN has enforced to establish a grievance/complain handling mechanism in every public sector including health [29]. In the health facility, suggestion or complaint box is the widely used tool for handling the grievances/complaints [22]. The box is placed in the premises of health facilities to receive the complaints and/or grievances from service users, communities as well as other stakeholders about the health services. Most of the time verbal grievances are likely to be addressed, hence, the complaints boxes in the health facilities are underutilized [22].

Moreover, MoHP Nepal has established the digital system to receive complaints via email and twitter [34]. Similarly, the MoHP has instructed hospitals, district public/ health offices to have their own website which includes information regarding organization, program, activities including budget and also has Facebook and Twitter account in order to foster accountability and transparency and improve access to the information [22]. Apart from that, $\mathrm{MOH}$ has initiated a digital monitoring campaign called 'Smart Health Nepal' via its website: www.mohp.gov.np [35]. It includes web-based information about the progress and achievement of NHSS-IP, information about the health facilities and available human resources as well as health sector planning, budget, expenditures, and progress [35].

\section{Community oversight}

In the health system, there is a different established structure that facilitates community oversight in social accountability interventions in maternal health services. The structures are presented below.

\section{Health Facility Operation Management Committee}

In line with the objective of Local Self-Governance Act 1999, MoHP devolved its power and responsibilities to the local body i.e. health facility operation and management committee (HFOMC) for the overall management of their respective health facility in 2000 [36, 37]. The committee is chaired by an elected representative; ward chairperson. The other members include; headteacher of the local school, one representative from the local business association, one FCHVs, ward secretary and one woman nominated by the chairperson. In-charge of health facility act as a member secretary of the committee 
[38]. Recently, the Constitution of Nepal 2015, has empowered the HFOMC with necessary responsibility for planning, implementation, and monitoring of the services of the health facility [38, 39].

According to the HFOMC guideline, the committee is required to meet once in a month to discuss the health facility issues and review the previous action plans, however, this is limited in practice [22, 38]. A national survey conducted in 2015 [37], reported that only $35 \%$ of health facilities had management meetings with community participation and only half of the committee members were engaged in the social audit process in six months preceding the survey. However, the survey was held in 2015 , at that time the committee did not have locally elected chairperson which could be one of the factor nonfunctional committee. Eventually, with the local level election in 2017, all the committees are being chaired by the locally elected chief, hopefully, this will bring an improvement [36].

The committee plays an influential role in raising resources for maternal health services in the community. They are the strong voice mechanism of the community in social accountability interventions as the committee constitute inclusive members [31, 38, 40]. In Nepal, the HFOMC found to more functional and also responsive toward addressing maternal health issues where social accountability interventions have been promoted $[24,36,41]$.

A review by Shakya et al. [42] reported increased numbers of birthing centres providing 24-hour services, availability of SBA at health facility, improved infection prevention practices and management of labour and delivery in rural health facilities where active engagement of HFOMC in accountability interventions is existed [42]. The findings are similar to other studies, done in Nepal. Conclusively, the health facility having active management committee are more likely to manage the resources and accountable to operate the birthing $24 / 7$ so as to improve the access to the services $[24,31,41,43]$.

\section{Female Community Health Volunteers (FCHVs)}

The female community health volunteer (FCHV) programme was initiated from in 1988 in Nepal. Initially, they were assigned to promote Family Planning (FP) services in the community. With a notable outcome of the programme, their role and responsibilities were gradually expanded to the continuum of care [44]. FCHVs are known for their remarkable contribution to the reduction of maternal and child morbidity and mortality in Nepal [3,45]. Similarly, they are a responsive member of the HFOMC [38]. Currently, 51,470 FCHVs (47,328 in rural and 4,142 in urban areas) are working across the country [3].

As a promoter of maternal and child health $(\mathrm{MCH})$ in community, they create awareness regarding birth preparedness to pregnant women and their family members and mothers' group through behaviour change communication (BCC) and other discussions held at the community [3,44]. The FCHVs liaison the Mothers' group and HFOMC in community level [46]. Moreover, they are initial reporting system in community-based MPDSR and voice mechanism of the marginalized and disadvantaged women in social accountability interventions [3, 22]. Being an important stakeholder of the community, they also monitor and evaluate the performance and quality of health services [44]. Recognizing their closeness with community people and their contribution in $\mathrm{MCH}$ sector, along with MoHP different development 
partners and government line agencies have mobilized them in health system strengthening programs $[22,41]$.

\section{- Mothers' Group for Health}

The mothers' group for health refers to the group of reproductive age women formed at the community with the initiation of the local health facility. The mothers' group have been recognized as an innovative strategy of community participation particularly women's participation that have been introduced to improve the $\mathrm{MCH}$ outcomes in Nepal [44]. The group members are responsible to select FCHV for their group $[41,44]$. Every month, the group members meet to discuss various $\mathrm{MCH}$ issues and best practices. Similarly, they are responsible to establish and maintain an emergency fund for obstetric services for their fellow group members [44]. In addition, they also monitor and evaluate the performances of FCHV on regular basis and make the FCHV accountable towards them [22, 44]. The health mothers' group is the voice mechanism to raise maternal health concerns in social accountability interventions [22].

A randomized controlled trial (RCT) in a rural part of Nepal, maternal mortality rate (MMR) decreased by $80 \%$ [adjusted odds ratio $(0.22,95 \% \mathrm{Cl} 0.05-0.90)$ ] in the women's group where community participation project with social accountability interventions was implemented in compare to the control group [47]. In addition infection prevention practice improved by twice among the birth attendees where the interventions were implemented and also improved maternal health service utilization among the trail groups [47].

Meanwhile, the meta-analysis of RCTs of the same intervention in four countries i.e. Bangladesh, India, Nepal, and Malawi [48] reported no significant differences in reduction of maternal mortality [OR 0.77 , $95 \% \mathrm{Cl}$ 0.48-1.23] [48]. The variation in the outcomes of each country led to further analysis of the trails. Eventually, subgroup analysis of the RCTs concluded, at least with $30 \%$ of women participation in the accountability intervention can reduce almost half $(49 \%)$ of the maternal mortality [OR $0.51,95 \% \mathrm{Cl} 0.29$ 0.89] [48]. The analysis evident inverse relationship between women participation in social accountability intervention and MMR. The intervention is also concluded as a cost-effective strategy to save women's life as per as WHO standard [48].

\section{Civil Society Organization}

In this review, the Civil Society Organizations (CSO) refer to the national and local NGOs working in the maternal health sector in Nepal. The CSOs have been identified as a strong community engagement and oversight mechanism in the accountability and governance process in Nepal's health sector [22, 49]. In regards to maternal health, they have played a vital role in advocacy for addressing maternal health problems and promoting accountability from centre to community level [41]. The local NGOs are mostly involved in implementing social accountability interventions either initiated by the government or development agencies. However, they themselves are a robust oversight system existed in the community in Nepal [22]. Some of the NGOs also provide preventive and promotive maternal health services and in some cases care too $[3,22]$. Meanwhile, INGOs provide technical and financial support to the government 
for the policy and guideline development and to implement social accountability interventions and strategies in the health sector $[3,22,24,50]$.

\section{Contextual factors influencing social accountability interventions in Nepal}

\section{Social-cultural context}

\section{Gender Norms}

Nepalese society is a typically patriarchal society where strong gender norms existed. Traditionally, men are privileged with power and position, as a result, women participation in the governance system is considerably low [51]. Therefore, to address the issue and empower women for their meaningful participation in each sector of development, GoN has made provision of reservation for women. $[39,49]$. Women's participation also has been ensured in the management committee of health facility through the mandatory provision of at least three women out of seven members in the committee, however, this is still restricted to the paper [38].

In one hand government has emphasized on women's and marginalized groups participation in each level of governance to enhance gender equality and social inclusion (GESI), while on another hand, due to unequal power relationship, low education, overloaded with household, productive and reproductive works, women tend to show less interest in participatory activities [51] like social audit, health management committee meetings etc. [22, 51, 52]. In most cases, women's presence in the meetings are just for token and they speak only if explicitly requested [51]. Hence women roles are confined only up to their physical presence at the programmes, while men are the ultimate decision-makers. [51]. However, evidence has shown that the increased women's involvement in participatory decision-making process results in a notable improvement in maternal health services which ultimately reduces maternal mortality and morbidity $[47,48,53]$.

\section{Social structure}

The country has a complex caste system with diverse ethnic groups [54] where the Brahman/Chhetri refers to upper caste and are most privileged group while the Dalit as disadvantaged caste and Janjati. indigenous group are the underprivileged groups in the country $[54,55]$. This caste-based social structure in Nepal has hindered the effective participation of the marginalized groups in the social accountability interventions [51]. Earlier there was mandatory reservation for a marginalized and disadvantaged member in the HFOMC, however, in 2019, the provision is abolished form the system. Now, they (one member from Dalit, disable and adolescent) are invitee member of the committee, who will not have an influencing role as a core member in the decision-making process [38]. 
"In the committee, most of the members are from higher castes. When we have meetings of the committee or any other programme, and when there is time for taking snacks, the other committee members sit a short distance away from me. There is thus still discrimination in our society. It [untouchability issue] is not in all places, but still exists with some people in some places. Due to this, it causes me stress inside. Then, how can I speak in the meeting or any events without hesitation?" [58].

There is a hegemony of the so-called higher caste group in the Nepalese society, still, major decisionmaking positions are held by them [32, 51]. Similarly, in the health sector, $50 \%$ of the health workers belong to the Brahman/Chhetri caste [56]. This caste hierarchy often produces unequal power relation between the service providers and service users where service users from the marginalized community have less power to negotiate for change in the health service providers attitude and behaviour $[32,56,57]$. In a qualitative study by Gurung et al, a Dalit member of the health management committee has stated how caste hierarchy system has suppressed their voice and participation in the accountability process [58].

Any form of discrimination is prohibited by law in Nepal, however, the issue of caste-based discrimination is still deeply deep-rooted in the community $[39,58,59]$. Hence, the existing informal power relationship and the dynamics of social structures needed to taken into consideration to ensure the effectiveness of the social accountability process.

\section{- Awareness, value, beliefs, and practices}

The effectiveness of social accountability interventions is often influenced by the level of people's awareness about their rights and entitlements, the existing governance mechanism to protect it and their role in it [14]. In Nepal, the majority of people are unaware of the concept of accountability and governance that makes difficult to hold service providers accountable for their action [22, 32]. Although, access to the information is a constitutional right of every Nepali citizen; women, poor and disadvantaged groups are less likely aware of their rights to get quality health services [39]. Meanwhile, literacy level, perception, and cultural beliefs are hindering factors for it [32,60]. A study in Nepal [61] has reported, citizen charter is not useful for illiterate people as they cannot read the information in it. Similarly, the list of free medicines written in English and displayed in the health facility is also useless as most people cannot read English. In both cases, the language is the barrier to access the information. The study also identified that people prefer television, radio or FCHV to get information about the health services which indicates changing preferences of people in accessing health information [61].

In Nepal, health belief and practices of people also influence the level of community participation in social accountability process [62]. In addition engaging youth and marginalized people in the social accountability interventions are difficult, as youth often hesitate to share their opinion in front of elders and mass respectively while marginalized people think their issues are irrelevant to be addressed. [62, 63]. A study was done by Gurung et al. identified despite having grievances and complaints regarding the quality of health services and provider's performance, in most cases, people have a tendency to stay silent and they are generally women, poor and marginalized group [64]. Eventually, those who complain 
they prefer/use informal channels like verbal complain mechanism such as direct talk to the person or via phone calls, through health management committee or FCHVs $[22,64]$. Similarly, in Nepalese society, the culture of raising questions and providing feedback to the power holders and prompt respond toward feedback is not properly established which also affect the community participation in the social accountability interventions [64].

\section{Political and economic context}

Nepal has gone through various political and structural transitions in the last two decades which had resulted in the unstable political situation in the country. The unstable political context created huge governance challenges in the country $[32,36]$. Similarly, the issue of political interference in the health sector has been also well reported. Often politic acts as a driving force in the formation and functioning of the health management committee [58] that interfere with the social accountability process [24, 36]. The decisions are often made on the political ground by the leaders rather than the community's concerns. The bureaucracy of health facility, kinship and health worker's power tend to determine the level of community participation in the accountability interventions $[36,58,65]$.

An evaluation study of the social accountability interventions has reported the issue of political pressure in the selection and retention of competent NGO to facilitate the social audit process in the health facilities. [24]. The political pressure generally comes through DHO/DPHO and LDO and sometimes intense pressure result in the replacement of experienced NGO with the favoured one which directly affects the quality implementation of social accountability interventions [24]. This kind of political influences tends to increase conflict of interest in social accountability interventions, process, and outcomes.

In Nepal, most of the health workers are associated with trade union and sister organization of political parties. They are often protected by associated political leadership for their actions. The health workers often use this nexus for their deployment and retention at well-facilitated places which have resulted in a persistent vacant post of regular and skilled staff in the remote health facilities, as the health workers prefer to stay in urban areas $[65,66]$. On the other hand, access to information, level of participation and ability to influence the responsiveness or decision making process in the health management committee are also determined by the economic status of the individual [36, 51, 64].

The business group have greater influence over the political infiltration and often resist the political intervention in the sphere of the economy in Nepal and they have been able to make the health sector a profit-making investment $[32,67]$. The running private and teaching hospitals becoming one of the

lucrative areas to get the best benefits out of the investment for business groups and politician [67]. This might potentially influence the responsiveness of policymaker toward community concerns. Therefore, it is essential to analyse and consider the influence of political-economic dynamics in social accountability interventions.

\section{Health system context}

Page 16/50 


\section{Client-provider relationship}

The health workers are recognized as an intellectual and respected personality in the community and their profession is perceived as a highly prestigious profession in Nepal [64]. Hence, the community hardly think that health workers commit any mistakes while providing and managing services. This perception often imbalances the power-relation between service users and providers, this, therefore, affect the dialogue processes in social accountability interventions [64]. On the other hand, the power relationship between service providers and service users particularly in remote areas where there are no choices for health services, the community often hesitate to complain or to provide feedback to the health workers in order to avoid unnecessary conflict and in the fear of getting poor quality of services in the next visit. A quote in the below box from a study of rural health facility reflects the perception of

\section{"How can Dalit, women, and the marginalized speak their minds with service providers? They think what the government does is all right. Health is the matter related to life and death. If you or your family member becomes ill, you have to go to the same place. Then, how could you take issue with the service providers? In villages, there is no option"- (Qualitative interview, staff, NGO) [64].}

the community toward accountability interventions [64].

Sometimes, the health workers and health facility committee members also tend to skip the interface with the community due to fear of being criticized in accountability interventions. [36, 68]. Furthermore, the people do not have access to have an interface with policy-level people as it is provisioned which has weakened the influence of social accountability interventions in the policy-level decision-making process [36].

\section{Resource availability}

Persistent resource deficiencies in the health sector are also identified factor limiting the health workers' and policymaker's responsiveness towards the community $[24,68]$. The management of the health facility has been handed to the local authority, however, human resource and logistics management are still being performed centrally which has undoubtedly made demand-supply procedure complex [22]. This has resulted in the frequent stock-outs of drugs and supplies and scarcity of human resources at health facilities level [33]. Moreover, in the federal government system, the line of accountability between Ministry of Health and Population, provincial and the local government has not been explicitly defined and also not properly guided which has further created responsibility dilemma among local authorities to manage health facilities under their responsibility $[22,59]$. As per new government structure, the local government has only provided with a budget for staff salaries and basic operation cost for health facility management which may be insufficient to fulfil the relevant health needs and priorities of the community raised up during social accountability interventions [22]. Additionally, due to the human resources gap at community level health facility, the FCHVs are overwhelmed with community-based health interventions like Safe Motherhood, FP, Immunization, Nutrition, MPDSR, mother groups meetings etc. They are also being used by other several sectors such as education, forest groups, micro-credit finance groups etc. for their own accountability purpose in the community [45]. In the end, they are a volunteer and only get 
event-based incentives, therefore, the increased volume of responsibilities with minimal incentive has resulted in a decrease in their motivation to work $[44,45]$. This might affect the quality service delivery and their responsiveness toward the community concerns.

In another argument, it has been said that organizational institutional capacity is equally important with the evidence of cases where allocated resources could not be mobilized and utilized properly due to lack of management capacity for improving the quality of health services [65].

\section{- Monitoring and evaluation}

In Nepal, the low responsiveness health system is often caused by the lack of proper monitoring and evaluation mechanism [7, 37]. Very few facilities, in fact, those facilities located at feasible geographic locations are frequently visited and receive regular supervision by the lined authorities [22, 65]. The district supervisors are often busy in conducting training and workshops which leave them with less time for supervision and monitoring at community-level health facilities [65]. This has weakened the effectiveness of established social accountability interventions in health facilities. The regular follow-up and analysis of audit action plans from the district and/or central level are almost non-existent in the health system $[22,24]$.

Evidence shows that demand-side social accountability interventions involve dialogue process which usually put soft pressure to the health workers to be accountable for their action and responsibility. It is argued that in the long run, without threat of sanction from the state, the interventions likely to address only surface level service delivery issues and affect the sustainability of the interventions [15]. Thus, the health system needs to strengthen the monitoring and supervision mechanism for effective and sustained outcomes of social accountability interventions.

\section{Evidence on the outcomes of social accountability interventions in maternal health services}

\section{Social audit}

There was no scientific research found examining the outcomes of social audit in Nepal, neither in other LMICs. Therefore, the findings from the evaluation and review study of social audit in Nepal has been presented as evidence.

Initiating the social audit intervention in health facilities has evident improved quality of maternal health services in Nepal. An evaluation study undertaken in health facilities of four districts of Nepal i.e. Palpa, Rupandehi, Jhapa and Ilam found overall improvement in the health provider's behaviour and attitude as well regularity of health service providers. The clients and patients received more equitable treatment and with dignity. Similarly, the ANC and institutional delivery incentives were timely provided to the beneficiaries. The interventions also improved the dialogue between the community, health service providers and health facility committee. Community concerns were incorporated with the health facility action plan. However, the impact level of the interventions was different in each study district [24]. It was 
more effective in Palpa and Rupandehi where the social audit was conducted on regular basis for a long time with the technical support of external development agency compared to Jhapa and llam where it was solely implemented by the Government without any support from development partners. [24]. Therefore, the result indicated the regular practice of social accountability interventions improves the outcomes.

Another review conducted to examine the effectiveness of social audit in rural health facilities in farwestern region one of the remotest regions in the country has identified social audit as an innovative and cost-effective strategy to improve health services quality. It is reported that social audit provides an opportunity for health workers and community leaders to be heard by policymakers. However, the sustainability of the intervention is still a question [68]. It depicted that specific attention is needed from policymakers to ensure enough budget allocation for the sustainability of the intervention, particularly for the facilities where intervention is supported by external development partners (EDPs).

\section{Maternal death review}

The maternal death review has been practised in Nepal for a long time and has also been scaled up in the different level of the health facilities $[3,27]$. However, no research has been carried out to examine the effectiveness and outcomes of the intervention in the context of Nepal, therefore, evidence from other LMICs having similar context has been presented.

A study in Bangladesh regarding MDR intervention reported the intervention helps to recognize the causes of maternal deaths in the community and bring the attention of decision-makers to respond and addressing the issues appropriately. The analysis of the cause of the maternal death resulted in deploying competent human resource such as MBBS doctor, SBA at birthing centres to manage complications, all necessary equipment and supplies were ensured that ultimately improved the QoC and provider-user satisfaction which resulted in the increased uptake of maternal health services in Bangladesh. Increased uptake of maternal health services led to reduction in maternal death [69].

A similar finding was reported in Nigeria where MDR played an influential role in improving health service provider's and policymaker's responsiveness toward addressing causes of maternal deaths. Due to the intervention, the state government of Nigeria showed a high level of political commitment to evidencebased strategy and interventions to improve the maternal health services [26].

Since, MoHP has already established a web-based system to capture maternal deaths, however, getting the data from health facilities is still an issue. With the available data, MoHP has able to identify the causes of death and action plans have been developed by MPDSR committee for a different level of care, however, implementation of those action plans are still a challenge. [3]. Nigeria also encountered a similar problem in death reporting and implementation of developed action plans in earlier days. However, they incorporate the scorecard to monitor whether the plan of action is developed and if recommendations are acted upon accordingly [26]. The intervention supported to improve the reporting and triggered the system to respond accordingly [26]. Taking into consideration of the experiences from Nigeria having similar 
health system context; this example can be applied in Nepal as well to overcome the challenges and improve the outcomes of the MDR/MPDSR intervention.

\section{Community scorecard/Community health scoreboard}

Based on the successful experience of CSC implemented in Malawi CARE-International has brought that concept customized tool; community health scoreboard (CHSB) and applied in Nepal to improve the maternal health outcomes [30, 70]. As no studies were found for analysis about the effectiveness of the tool for improved maternal health outcomes in Nepal; evidence from other LMICS has been presented to show the relationship between tool and maternal health outcomes.

In Malawi, the intervention supported to increase interaction between the health service providers, members of the health committee and community, this improved accountability of health worker as well as improved the quality ANC and PNC services. As women were treated better at health facilities, the maternal service utilization trend increased [70]. Improved quality of maternal health services, access to and utilization of the maternal health services were achieved through mutually developed action plans [70]. The intervention particularly had more impact on the indicators that required little or no resources from the government [70]. As it was implemented at the community level health facility, the tool no significant impact on the indicators which needed the attention of higher-level government authorities [70]. This finding is similar to findings of an evaluation of social audit done in Nepal [24].

A mixed-method study performed in 2016 in Ghana to examine the effectiveness of CSC for improved maternal and newborn health services reported improved quality of emergency obstetric and newborn care (EmONC) in intervention piloted health facilities while the intervention improved engagement of stakeholders and community in the process [71]. The process also supported to develop a shared responsibility also termed 'horizontal accountability' and created ownership among the community and stakeholders for both challenges and solutions, ultimately improved management of equipment and infrastructure in majority of health facilities [71].

Looking at the contextual similarities of Malawi and Ghana, Nepal can also expect similar outcomes of the CSC and/or CHSB in maternal health services. However, the sustainability of the interventions in Nepal is a major challenge as the interventions are promoted by the donor with minimal involvement of government [36]. Meanwhile, the government can integrate the CSC/CHSB in the social audit for efficiency and sustainability purpose. As an example in Zambia, CSC was combined with a social audit to enhance the responsiveness of the service providers and improve the coordination between state and community [72]. In the country, the social audit is used to assess the service performance against the national standard and the CSC is to rate the health facility against the perception-based indicators [72]. Taking the best practice from Zambia, Nepal can also adopt similar modality to sustain the intervention.

\section{Citizen charter and complain/grievances handling interventions}


No evidence is found on the contribution/effectiveness in the maternal health services in Nepal as well as in the other LMICs. Eventually, a study mapping awareness and factor influencing the implementation of citizen charter in health facility concluded it promotes the transparency of health facility and accountability of health workers towards service users if well implemented [61]. The similar conclusion was drawn in a study conducted in Kenya [73].

Although the complaint/grievances box contributes to enhancing accountability and transparency their uses are limited in practice and no specific attention has been given by the state. Many health facilities were found not to have citizen charter in the place and the complaint boxes often go unused and found to be filling with dust and spider webs $[22,61,64]$. The statement in the below box from a study in Nepal highlights the attitude of health worker on the usefulness of complaint box [64].

"... not only at the health facility level but even at the district level, the situation is that suggestion boxes are filled up with 'spider webs'. As far as I know the suggestion box is not in use. No one puts their complaints or suggestions [into the suggestion box] by writing onto a piece of paper. Many do not know about its existence. So I do not see any importance of it"- PHC clinic manager [64].

A report by Commissions for the Investigation of Abuse of Authority (CIAA, the health sector in Nepal is in $5^{\text {th }}$ place amongst 9 sectors for the highest number of complaint about power abuse which indicated potential corruption vulnerabilities in the health system [74]. In such cases, poor information dissemination mechanism might result in information asymmetry between providers and users ultimately affect the quality of the service delivery. In addition, without informing the community could not evaluate the components of QoC in maternal health services and also unable to claim their rights entitlements ultimately lead to superficial community participation and produce suboptimal outcomes [75].

In Nepal, $20 \%$ of the estimated population is using the internet to access information and the trend is increasing, therefore, this indicates the possibility to use the digital media to improve information access so as to create the demand for quality health services [76]. A digital campaign has already been practising in sub-Saharan African countries with the support of the Evidence for Action (E4A) programme i.e. 'Mama Ye!' public engagement campaign [77]. The campaign is to create pressure on policymakers for their commitment and respond in prioritizing quality maternal and neonatal health services through digital media approaches [77]. The strategy could be relevant to the Nepalese context to create demand 
of quality maternal health service and make service providers accountable toward their actions and responsibility, while people's preference for accessing health information and providing feedback is changing accordingly to the advancement of the technology in Nepal [22, 36, 64].

\section{Social accountability interventions in maternal health services in Nepal}

\section{Community engagement}

In Nepal, it is found that different social accountability tools have been used and tested either by government or development partners to ensure community engagement in social accountability interventions in maternal health services. The common tools used in maternal health services are described below.

\section{Social Audit}

The social audit has been initiated by the GoN since 2009 to ensure the quality implementation of Aama program $[22,23]$. The main aim of this initiation is to increase women's and community awareness, promote transparency in the decision process of health facility, make the health workers and decisionmakers accountable and responsive for quality maternal health services, set a culture of demand for information from the health facility as well as strengthen mutual accountability between service providers and users [23].

The programme has been implemented through the local non-government organization (NGO) who are identified through a competitive process $[23,24]$. The NGOs facilitate the process of social audit where community and local stakeholders are invited to review the performance, identify existing problems and challenges of the health facility as well as develop an action plan for improving quality of services. The process takes 5-6 days to complete in one health facility in the initial stage. However, time implication is less in the follow-up programme [24].

The outcomes of social audit are supposed to be reviewed in district as well as regional level programme review meeting and provide necessary feedback to the concerned district and health facility on their action plan. However, the meetings usually limited to compiling the reports, rather than analysis of the results and quality of the process [22, 24]. Up to fiscal year 2016/17, the program has been scaled up to 70 districts out of 77 . The social audit was done in 1752 health facilities the up to 25 bed in the last fiscal year. The Government has a plan to scale up the program into all 77 districts by $2020[7,24]$.

\section{Maternal Perinatal Death Surveillance and Response (MPDSR)}

The WHO has recognized the Maternal Death Review (MDR) as a relevant accountability tool for improved quality of the maternal and neonatal health $(\mathrm{MNH})$ services which are based on the concept of the monitor-review-act cycle [25-27]. The process involves national-level monitoring and oversight of the results, multi-stakeholder analysis and action and all components of surveillance and responses systems [26]. 
The GoN firstly initiated the program in 1990 at the tertiary level hospital with the support of the WHO. Since then it has been scaled up at different levels of care at different phases with improvisation from the learnings of the programs. [27]. Recently, the government merged this MDR program with Maternal Perinatal Death Review (MPDR) program and developed a comprehensive surveillance system named 'Maternal Perinatal Death Surveillance and Response' (MPDSR). There are two types of MPDSR; facilitybased and community-based in Nepal $[3,27]$. It is a supply-side accountability intervention initiated to improve quality of maternal health services which is focused on routine identification and notification of maternal and perinatal deaths, determinants of death causes and use of the information to improve quality of care as well as management of the program to avoid future deaths [27]. The community-based intervention has been implemented in 6 districts whereas facility-based intervention has been expanded in 65 hospitals in 38 districts [3]. For the implementation, the committee is formed at district, hospital and local health facilities level. At the local level committee, there is a separate verbal autopsy and cause of death assignment team [3]. Fig 2 shows the process of the MPDSR.

Despite the effort, the implementation of the intervention is challenged by underreporting, delay reporting and incomplete reporting of death from peripheral health facilities, geographical difficulties and resources constraints [3].

Fig 3 Process of MPDSR at community and health facility level [3].

\section{- Community Score Card/Community Health Score Board}

Both community scorecard (CSC) and community health scoreboard (CHSB) are introduced at the same time in Nepal to promote health sector accountability. CSC is a tool designed to promote participation, transparency, and accountability among service providers, service users and decision-makers. The tool provides an opportunity for the community to evaluate the quality of services, express their dissatisfaction and voice health rights $[28,29]$. It is a process-oriented tool, where community people along with service providers and stakeholders monitor and evaluate health service against agreed indicators. With the support of indicators, quality of services, health facility performance, and health governance are monitored using define scale or score. At the end of the process, people along with service providers develop an action plan and prioritize the activities based on the given score for further improvement [29]. The tool was piloted in 16 health posts by the Government with support of World Bank in 2011 [28, 29] which was found effective for promoting direct feedback mechanism and efficient use of resources at a health facility. However, due to high implementation cost and lack of competent human resources for the facilitation of the process the government could not scale-up further [22, 28, 29].

As a hybrid form of participatory rural appraisal (PRA), social audit and CSC, community health scoreboard (CHSB) has been introduced in maternal, neonatal and child health (MNCH) services with the support of CARE-Nepal $[22,30]$. The tool is based on the value and principle of community participation. The tool creates an environment for tri-party dialogue among service providers, beneficiaries and 
decision-makers which facilitates monitoring and performance of $\mathrm{MNCH}$ services [30, 31]. The dialogue is based on the indicators developed with the consultation with the district health office/district public health office (DHO/DPHO) [30]. Similar to the CSC, community people, service providers, and decisionmakers jointly discuss the $\mathrm{MNCH}$ issues and then provide mutually agreed scores on the performance indicators and develop action plans for further improvement. The action plans are reviewed semiannually following the same process. It provides an opportunity for immediate feedback to services provider and decision-makers and respond toward raised concerns $[22,30]$.

\section{Citizen Charter}

Citizen charter is an information board, displayed at all public service centres. It is a tool to ensure the constitutional right of the Nepali citizen to the information as well as express the government commitment for providing quality services in a transparent and accountable way [29]. The citizen charter includes the information about the availability of services, essential requirement to get services, name of the contact person, required time and name of the person to redress the grievances if any. The board also includes the information about the day, time and duration of services; fee/charges of services like labtest, $x$-ray; list of free health services and drugs; incentives information; terms and procedure; responsible health workers, etc. $[22,29]$. Since 2007 , GoN has made it mandatory to display it at clearly visible premises of all public office/facilities and this applied in the health sector as well [29, 32].

The tool has been promoted in the health sector to ensure transparency, improve service providers' accountability, make the service users informed about the services and address the concern/grievances of citizen about the services [33], however, many gaps have been identified in posting information about the availability of essential drugs and services in the health facilities [33]. A report in social accountability in the health sector [22] stated that $29 \%$ of health facilities do not have citizen charter at their premises. And if the health facilities have, it hasn't been displaying properly [22]. Eventually, the weak enforceability mechanism in the health sector is one of the reason for it $[22,33]$.

\section{Grievance/Complaint handling tool}

The GoN has enforced to establish a grievance/complain handling mechanism in every public sector including health [29]. In the health facility, suggestion or complaint box is the widely used tool for handling the grievances/complaints [22]. The box is placed in the premises of health facilities to receive the complaints and/or grievances from service users, communities as well as other stakeholders about the health services. Most of the time verbal grievances are likely to be addressed, hence, the complaints boxes in the health facilities are underutilized [22].

Moreover, MoHP Nepal has established the digital system to receive complaints via email and twitter [34]. Similarly, the MoHP has instructed hospitals, district public/ health offices to have their own website which includes information regarding organization, program, activities including budget and also has Facebook and Twitter account in order to foster accountability and transparency and improve access to the information [22]. Apart from that, $\mathrm{MOH}$ has initiated a digital monitoring campaign called 'Smart 
Health Nepal' via its website: www.mohp.gov.np [35]. It includes web-based information about the progress and achievement of NHSS-IP, information about the health facilities and available human resources as well as health sector planning, budget, expenditures, and progress [35].

\section{Community oversight}

In the health system, there is a different established structure that facilitates community oversight in social accountability interventions in maternal health services. The structures are presented below.

\section{Health Facility Operation Management Committee}

In line with the objective of Local Self-Governance Act 1999, MoHP devolved its power and responsibilities to the local body i.e. health facility operation and management committee (HFOMC) for the overall management of their respective health facility in 2000 [36, 37]. The committee is chaired by an elected representative; ward chairperson. The other members include; headteacher of the local school, one representative from the local business association, one FCHVs, ward secretary and one woman nominated by the chairperson. In-charge of health facility act as a member secretary of the committee [38]. Recently, the Constitution of Nepal 2015, has empowered the HFOMC with necessary responsibility for planning, implementation, and monitoring of the services of the health facility $[38,39]$.

According to the HFOMC guideline, the committee is required to meet once in a month to discuss the health facility issues and review the previous action plans, however, this is limited in practice [22, 38]. A national survey conducted in 2015 [37], reported that only 35\% of health facilities had management meetings with community participation and only half of the committee members were engaged in the social audit process in six months preceding the survey. However, the survey was held in 2015, at that time the committee did not have locally elected chairperson which could be one of the factor nonfunctional committee. Eventually, with the local level election in 2017, all the committees are being chaired by the locally elected chief, hopefully, this will bring an improvement [36].

The committee plays an influential role in raising resources for maternal health services in the community. They are the strong voice mechanism of the community in social accountability interventions as the committee constitute inclusive members [31, 38, 40]. In Nepal, the HFOMC found to more functional and also responsive toward addressing maternal health issues where social accountability interventions have been promoted $[24,36,41]$.

A review by Shakya et al. [42] reported increased numbers of birthing centres providing 24-hour services, availability of SBA at health facility, improved infection prevention practices and management of labour and delivery in rural health facilities where active engagement of HFOMC in accountability interventions is existed [42]. The findings are similar to other studies, done in Nepal. Conclusively, the health facility having active management committee are more likely to manage the resources and accountable to operate the birthing $24 / 7$ so as to improve the access to the services $[24,31,41,43]$.

\section{Female Community Health Volunteers (FCHVs)}


The female community health volunteer (FCHV) programme was initiated from in 1988 in Nepal. Initially, they were assigned to promote Family Planning (FP) services in the community. With a notable outcome of the programme, their role and responsibilities were gradually expanded to the continuum of care [44]. FCHVs are known for their remarkable contribution to the reduction of maternal and child morbidity and mortality in Nepal [3,45]. Similarly, they are a responsive member of the HFOMC [38]. Currently, 51,470 FCHVs (47,328 in rural and 4,142 in urban areas) are working across the country [3].

As a promoter of maternal and child health $(\mathrm{MCH})$ in community, they create awareness regarding birth preparedness to pregnant women and their family members and mothers' group through behaviour change communication (BCC) and other discussions held at the community [3, 44]. The FCHVs liaison the Mothers' group and HFOMC in community level [46]. Moreover, they are initial reporting system in community-based MPDSR and voice mechanism of the marginalized and disadvantaged women in social accountability interventions $[3,22]$. Being an important stakeholder of the community, they also monitor and evaluate the performance and quality of health services [44]. Recognizing their closeness with community people and their contribution in $\mathrm{MCH}$ sector, along with MoHP different development partners and government line agencies have mobilized them in health system strengthening programs $[22,41]$.

\section{- Mothers' Group for Health}

The mothers' group for health refers to the group of reproductive age women formed at the community with the initiation of the local health facility. The mothers' group have been recognized as an innovative strategy of community participation particularly women's participation that have been introduced to improve the $\mathrm{MCH}$ outcomes in Nepal [44]. The group members are responsible to select FCHV for their group [41, 44]. Every month, the group members meet to discuss various $\mathrm{MCH}$ issues and best practices. Similarly, they are responsible to establish and maintain an emergency fund for obstetric services for their fellow group members [44]. In addition, they also monitor and evaluate the performances of FCHV on regular basis and make the FCHV accountable towards them [22, 44]. The health mothers' group is the voice mechanism to raise maternal health concerns in social accountability interventions [22].

A randomized controlled trial (RCT) in a rural part of Nepal, maternal mortality rate (MMR) decreased by $80 \%$ [adjusted odds ratio $(0.22,95 \% \mathrm{Cl} 0.05-0.90)$ ] in the women's group where community participation project with social accountability interventions was implemented in compare to the control group [47]. In addition infection prevention practice improved by twice among the birth attendees where the interventions were implemented and also improved maternal health service utilization among the trail groups [47].

Meanwhile, the meta-analysis of RCTs of the same intervention in four countries i.e. Bangladesh, India, Nepal, and Malawi [48] reported no significant differences in reduction of maternal mortality [OR 0.77 , 95\% $\mathrm{Cl}$ 0.48-1.23] [48]. The variation in the outcomes of each country led to further analysis of the trails. Eventually, subgroup analysis of the RCTs concluded, at least with $30 \%$ of women participation in the accountability intervention can reduce almost half (49\%) of the maternal mortality [OR $0.51,95 \% \mathrm{Cl} 0.29$ - 
0.89] [48]. The analysis evident inverse relationship between women participation in social accountability intervention and MMR. The intervention is also concluded as a cost-effective strategy to save women's life as per as WHO standard [48].

\section{Civil Society Organization}

In this review, the Civil Society Organizations (CSO) refer to the national and local NGOs working in the maternal health sector in Nepal. The CSOs have been identified as a strong community engagement and oversight mechanism in the accountability and governance process in Nepal's health sector [22, 49]. In regards to maternal health, they have played a vital role in advocacy for addressing maternal health problems and promoting accountability from centre to community level [41]. The local NGOs are mostly involved in implementing social accountability interventions either initiated by the government or development agencies. However, they themselves are a robust oversight system existed in the community in Nepal [22]. Some of the NGOs also provide preventive and promotive maternal health services and in some cases care too $[3,22]$. Meanwhile, INGOs provide technical and financial support to the government for the policy and guideline development and to implement social accountability interventions and strategies in the health sector $[3,22,24,50]$.

\section{Contextual factors influencing social accountability interventions in Nepal}

\section{Social-cultural context}

\section{Gender Norms}

Nepalese society is a typically patriarchal society where strong gender norms existed. Traditionally, men are privileged with power and position, as a result, women participation in the governance system is considerably low [51]. Therefore, to address the issue and empower women for their meaningful participation in each sector of development, GoN has made provision of reservation for women. $[39,49]$. Women's participation also has been ensured in the management committee of health facility through the mandatory provision of at least three women out of seven members in the committee, however, this is still restricted to the paper [38].

In one hand government has emphasized on women's and marginalized groups participation in each level of governance to enhance gender equality and social inclusion (GESI), while on another hand, due to unequal power relationship, low education, overloaded with household, productive and reproductive works, women tend to show less interest in participatory activities [51] like social audit, health management committee meetings etc. [22, 51, 52]. In most cases, women's presence in the meetings are just for token and they speak only if explicitly requested [51]. Hence women roles are confined only up to their physical presence at the programmes, while men are the ultimate decision-makers. [51]. However, evidence has shown that the increased women's involvement in participatory decision-making process results in a notable improvement in maternal health services which ultimately reduces maternal mortality and morbidity $[47,48,53]$. 


\section{Social structure}

The country has a complex caste system with diverse ethnic groups [54] where the Brahman/Chhetri refers to upper caste and are most privileged group while the Dalit as disadvantaged caste and Janjati. indigenous group are the underprivileged groups in the country $[54,55]$. This caste-based social structure in Nepal has hindered the effective participation of the marginalized groups in the social accountability interventions [51]. Earlier there was mandatory reservation for a marginalized and disadvantaged member in the HFOMC, however, in 2019, the provision is abolished form the system. Now, they (one member from Dalit, disable and adolescent) are invitee member of the committee, who will not have an influencing role as a core member in the decision-making process [38].

"In the committee, most of the members are from higher castes. When we have meetings of the committee or any other programme, and when there is time for taking snacks, the other committee members sit a short distance away from me. There is thus still discrimination in our society. It [untouchability issue] is not in all places, but still exists with some people in some places. Due to this, it causes me stress inside. Then, how can I speak in the meeting or any events without hesitation?" [58].

There is a hegemony of the so-called higher caste group in the Nepalese society, still, major decisionmaking positions are held by them $[32,51]$. Similarly, in the health sector, $50 \%$ of the health workers belong to the Brahman/Chhetri caste [56]. This caste hierarchy often produces unequal power relation between the service providers and service users where service users from the marginalized community have less power to negotiate for change in the health service providers attitude and behaviour $[32,56,57]$. In a qualitative study by Gurung et al, a Dalit member of the health management committee has stated how caste hierarchy system has suppressed their voice and participation in the accountability process [58].

Any form of discrimination is prohibited by law in Nepal, however, the issue of caste-based discrimination is still deeply deep-rooted in the community $[39,58,59]$. Hence, the existing informal power relationship and the dynamics of social structures needed to taken into consideration to ensure the effectiveness of the social accountability process.

\section{- Awareness, value, beliefs, and practices}

The effectiveness of social accountability interventions is often influenced by the level of people's awareness about their rights and entitlements, the existing governance mechanism to protect it and their role in it [14]. In Nepal, the majority of people are unaware of the concept of accountability and governance that makes difficult to hold service providers accountable for their action [22, 32]. Although, access to the information is a constitutional right of every Nepali citizen; women, poor and disadvantaged groups are less likely aware of their rights to get quality health services [39]. Meanwhile, literacy level, perception, and cultural beliefs are hindering factors for it [32,60]. A study in Nepal [61] has reported, citizen charter is not useful for illiterate people as they cannot read the information in it. Similarly, the list of free medicines written in English and displayed in the health facility is also useless as 
most people cannot read English. In both cases, the language is the barrier to access the information. The study also identified that people prefer television, radio or FCHV to get information about the health services which indicates changing preferences of people in accessing health information [61].

In Nepal, health belief and practices of people also influence the level of community participation in social accountability process [62]. In addition engaging youth and marginalized people in the social accountability interventions are difficult, as youth often hesitate to share their opinion in front of elders and mass respectively while marginalized people think their issues are irrelevant to be addressed. [62, 63]. A study was done by Gurung et al. identified despite having grievances and complaints regarding the quality of health services and provider's performance, in most cases, people have a tendency to stay silent and they are generally women, poor and marginalized group [64]. Eventually, those who complain they prefer/use informal channels like verbal complain mechanism such as direct talk to the person or via phone calls, through health management committee or FCHVs $[22,64]$. Similarly, in Nepalese society, the culture of raising questions and providing feedback to the power holders and prompt respond toward feedback is not properly established which also affect the community participation in the social accountability interventions [64].

\section{Political and economic context}

Nepal has gone through various political and structural transitions in the last two decades which had resulted in the unstable political situation in the country. The unstable political context created huge governance challenges in the country $[32,36]$. Similarly, the issue of political interference in the health sector has been also well reported. Often politic acts as a driving force in the formation and functioning of the health management committee [58] that interfere with the social accountability process [24, 36]. The decisions are often made on the political ground by the leaders rather than the community's concerns. The bureaucracy of health facility, kinship and health worker's power tend to determine the level of community participation in the accountability interventions $[36,58,65]$.

An evaluation study of the social accountability interventions has reported the issue of political pressure in the selection and retention of competent NGO to facilitate the social audit process in the health facilities. [24]. The political pressure generally comes through DHO/DPHO and LDO and sometimes intense pressure result in the replacement of experienced NGO with the favoured one which directly affects the quality implementation of social accountability interventions [24]. This kind of political influences tends to increase conflict of interest in social accountability interventions, process, and outcomes.

In Nepal, most of the health workers are associated with trade union and sister organization of political parties. They are often protected by associated political leadership for their actions. The health workers often use this nexus for their deployment and retention at well-facilitated places which have resulted in a persistent vacant post of regular and skilled staff in the remote health facilities, as the health workers prefer to stay in urban areas $[65,66]$. On the other hand, access to information, level of participation and 
ability to influence the responsiveness or decision making process in the health management committee are also determined by the economic status of the individual $[36,51,64]$.

The business group have greater influence over the political infiltration and often resist the political intervention in the sphere of the economy in Nepal and they have been able to make the health sector a profit-making investment $[32,67]$. The running private and teaching hospitals becoming one of the lucrative areas to get the best benefits out of the investment for business groups and politician [67]. This might potentially influence the responsiveness of policymaker toward community concerns. Therefore, it is essential to analyse and consider the influence of political-economic dynamics in social accountability interventions.

\section{Health system context}

\section{Client-provider relationship}

The health workers are recognized as an intellectual and respected personality in the community and their profession is perceived as a highly prestigious profession in Nepal [64]. Hence, the community hardly think that health workers commit any mistakes while providing and managing services. This perception often imbalances the power-relation between service users and providers, this, therefore, affect the dialogue processes in social accountability interventions [64]. On the other hand, the power relationship between service providers and service users particularly in remote areas where there are no choices for health services, the community often hesitate to complain or to provide feedback to the health workers in order to avoid unnecessary conflict and in the fear of getting poor quality of services in the next visit. A quote in the below box from a study of rural health facility reflects the perception of

\section{"How can Dalit, women, and the marginalized speak their minds with service providers? They think what the government does is all right. Health is the matter related to life and death. If you or your family member becomes ill, you have to go to the same place. Then, how could you take issue with the service providers? In villages, there is no option"- (Qualitative interview, staff, NGO) [64].}

the community toward accountability interventions [64].

Sometimes, the health workers and health facility committee members also tend to skip the interface with the community due to fear of being criticized in accountability interventions. [36, 68]. Furthermore, the people do not have access to have an interface with policy-level people as it is provisioned which has weakened the influence of social accountability interventions in the policy-level decision-making process [36].

\section{Resource availability}

Persistent resource deficiencies in the health sector are also identified factor limiting the health workers' and policymaker's responsiveness towards the community $[24,68]$. The management of the health facility has been handed to the local authority, however, human resource and logistics management are still being performed centrally which has undoubtedly made demand-supply procedure complex [22]. This 
has resulted in the frequent stock-outs of drugs and supplies and scarcity of human resources at health facilities level [33]. Moreover, in the federal government system, the line of accountability between Ministry of Health and Population, provincial and the local government has not been explicitly defined and also not properly guided which has further created responsibility dilemma among local authorities to manage health facilities under their responsibility $[22,59]$. As per new government structure, the local government has only provided with a budget for staff salaries and basic operation cost for health facility management which may be insufficient to fulfil the relevant health needs and priorities of the community raised up during social accountability interventions [22]. Additionally, due to the human resources gap at community level health facility, the FCHVs are overwhelmed with community-based health interventions like Safe Motherhood, FP, Immunization, Nutrition, MPDSR, mother groups meetings etc. They are also being used by other several sectors such as education, forest groups, micro-credit finance groups etc. for their own accountability purpose in the community [45]. In the end, they are a volunteer and only get event-based incentives, therefore, the increased volume of responsibilities with minimal incentive has resulted in a decrease in their motivation to work $[44,45]$. This might affect the quality service delivery and their responsiveness toward the community concerns.

In another argument, it has been said that organizational institutional capacity is equally important with the evidence of cases where allocated resources could not be mobilized and utilized properly due to lack of management capacity for improving the quality of health services [65].

\section{- Monitoring and evaluation}

In Nepal, the low responsiveness health system is often caused by the lack of proper monitoring and evaluation mechanism [7, 37]. Very few facilities, in fact, those facilities located at feasible geographic locations are frequently visited and receive regular supervision by the lined authorities [22, 65]. The district supervisors are often busy in conducting training and workshops which leave them with less time for supervision and monitoring at community-level health facilities [65]. This has weakened the effectiveness of established social accountability interventions in health facilities. The regular follow-up and analysis of audit action plans from the district and/or central level are almost non-existent in the health system $[22,24]$.

Evidence shows that demand-side social accountability interventions involve dialogue process which usually put soft pressure to the health workers to be accountable for their action and responsibility. It is argued that in the long run, without threat of sanction from the state, the interventions likely to address only surface level service delivery issues and affect the sustainability of the interventions [15]. Thus, the health system needs to strengthen the monitoring and supervision mechanism for effective and sustained outcomes of social accountability interventions.

\section{Evidence on the outcomes of social accountability interventions in maternal health services}

\section{Social audit}


There was no scientific research found examining the outcomes of social audit in Nepal, neither in other LMICs. Therefore, the findings from the evaluation and review study of social audit in Nepal has been presented as evidence.

Initiating the social audit intervention in health facilities has evident improved quality of maternal health services in Nepal. An evaluation study undertaken in health facilities of four districts of Nepal i.e. Palpa, Rupandehi, Jhapa and llam found overall improvement in the health provider's behaviour and attitude as well regularity of health service providers. The clients and patients received more equitable treatment and with dignity. Similarly, the ANC and institutional delivery incentives were timely provided to the beneficiaries. The interventions also improved the dialogue between the community, health service providers and health facility committee. Community concerns were incorporated with the health facility action plan. However, the impact level of the interventions was different in each study district [24]. It was more effective in Palpa and Rupandehi where the social audit was conducted on regular basis for a long time with the technical support of external development agency compared to Jhapa and llam where it was solely implemented by the Government without any support from development partners. [24]. Therefore, the result indicated the regular practice of social accountability interventions improves the outcomes.

Another review conducted to examine the effectiveness of social audit in rural health facilities in farwestern region one of the remotest regions in the country has identified social audit as an innovative and cost-effective strategy to improve health services quality. It is reported that social audit provides an

opportunity for health workers and community leaders to be heard by policymakers. However, the sustainability of the intervention is still a question [68]. It depicted that specific attention is needed from policymakers to ensure enough budget allocation for the sustainability of the intervention, particularly for the facilities where intervention is supported by external development partners (EDPs).

\section{Maternal death review}

The maternal death review has been practised in Nepal for a long time and has also been scaled up in the different level of the health facilities $[3,27]$. However, no research has been carried out to examine the effectiveness and outcomes of the intervention in the context of Nepal, therefore, evidence from other LMICs having similar context has been presented.

A study in Bangladesh regarding MDR intervention reported the intervention helps to recognize the causes of maternal deaths in the community and bring the attention of decision-makers to respond and addressing the issues appropriately. The analysis of the cause of the maternal death resulted in deploying competent human resource such as MBBS doctor, SBA at birthing centres to manage complications, all necessary equipment and supplies were ensured that ultimately improved the QoC and provider-user satisfaction which resulted in the increased uptake of maternal health services in Bangladesh. Increased uptake of maternal health services led to reduction in maternal death [69]. 
A similar finding was reported in Nigeria where MDR played an influential role in improving health service provider's and policymaker's responsiveness toward addressing causes of maternal deaths. Due to the intervention, the state government of Nigeria showed a high level of political commitment to evidencebased strategy and interventions to improve the maternal health services [26].

Since, MoHP has already established a web-based system to capture maternal deaths, however, getting the data from health facilities is still an issue. With the available data, MoHP has able to identify the causes of death and action plans have been developed by MPDSR committee for a different level of care, however, implementation of those action plans are still a challenge. [3]. Nigeria also encountered a similar problem in death reporting and implementation of developed action plans in earlier days. However, they incorporate the scorecard to monitor whether the plan of action is developed and if recommendations are acted upon accordingly [26]. The intervention supported to improve the reporting and triggered the system to respond accordingly [26]. Taking into consideration of the experiences from Nigeria having similar health system context; this example can be applied in Nepal as well to overcome the challenges and improve the outcomes of the MDR/MPDSR intervention.

\section{Community scorecard/Community health scoreboard}

Based on the successful experience of CSC implemented in Malawi CARE-International has brought that concept customized tool; community health scoreboard (CHSB) and applied in Nepal to improve the maternal health outcomes [30, 70]. As no studies were found for analysis about the effectiveness of the tool for improved maternal health outcomes in Nepal; evidence from other LMICS has been presented to show the relationship between tool and maternal health outcomes.

In Malawi, the intervention supported to increase interaction between the health service providers, members of the health committee and community, this improved accountability of health worker as well as improved the quality ANC and PNC services. As women were treated better at health facilities, the maternal service utilization trend increased [70]. Improved quality of maternal health services, access to and utilization of the maternal health services were achieved through mutually developed action plans [70]. The intervention particularly had more impact on the indicators that required little or no resources from the government [70]. As it was implemented at the community level health facility, the tool no significant impact on the indicators which needed the attention of higher-level government authorities [70]. This finding is similar to findings of an evaluation of social audit done in Nepal [24].

A mixed-method study performed in 2016 in Ghana to examine the effectiveness of CSC for improved maternal and newborn health services reported improved quality of emergency obstetric and newborn care (EmONC) in intervention piloted health facilities while the intervention improved engagement of stakeholders and community in the process [71]. The process also supported to develop a shared responsibility also termed 'horizontal accountability' and created ownership among the community and stakeholders for both challenges and solutions, ultimately improved management of equipment and infrastructure in majority of health facilities [71]. 
Looking at the contextual similarities of Malawi and Ghana, Nepal can also expect similar outcomes of the CSC and/or CHSB in maternal health services. However, the sustainability of the interventions in Nepal is a major challenge as the interventions are promoted by the donor with minimal involvement of government [36]. Meanwhile, the government can integrate the CSC/CHSB in the social audit for efficiency and sustainability purpose. As an example in Zambia, CSC was combined with a social audit to enhance the responsiveness of the service providers and improve the coordination between state and community [72]. In the country, the social audit is used to assess the service performance against the national standard and the CSC is to rate the health facility against the perception-based indicators [72]. Taking the best practice from Zambia, Nepal can also adopt similar modality to sustain the intervention.

\section{Citizen charter and complain/grievances handling interventions}

No evidence is found on the contribution/effectiveness in the maternal health services in Nepal as well as in the other LMICs. Eventually, a study mapping awareness and factor influencing the implementation of citizen charter in health facility concluded it promotes the transparency of health facility and accountability of health workers towards service users if well implemented [61]. The similar conclusion was drawn in a study conducted in Kenya [73].

Although the complaint/grievances box contributes to enhancing accountability and transparency their uses are limited in practice and no specific attention has been given by the state. Many health facilities were found not to have citizen charter in the place and the complaint boxes often go unused and found to be filling with dust and spider webs $[22,61,64]$. The statement in the below box from a study in Nepal highlights the attitude of health worker on the usefulness of complaint box [64].

"... not only at the health facility level but even at the district level, the situation is that suggestion boxes are filled up with 'spider webs'. As far as I know the suggestion box is not in use. No one puts their complaints or suggestions [into the suggestion box] by writing onto a piece of paper. Many do not know about its existence. So I do not see any importance of it"- PHC clinic manager [64].

A report by Commissions for the Investigation of Abuse of Authority (CIAA, the health sector in Nepal is in $5^{\text {th }}$ place amongst 9 sectors for the highest number of complaint about power abuse which indicated potential corruption vulnerabilities in the health system [74]. In such cases, poor information 
dissemination mechanism might result in information asymmetry between providers and users ultimately affect the quality of the service delivery. In addition, without informing the community could not evaluate the components of QoC in maternal health services and also unable to claim their rights entitlements ultimately lead to superficial community participation and produce suboptimal outcomes [75].

In Nepal, $20 \%$ of the estimated population is using the internet to access information and the trend is increasing, therefore, this indicates the possibility to use the digital media to improve information access so as to create the demand for quality health services [76]. A digital campaign has already been practising in sub-Saharan African countries with the support of the Evidence for Action (E4A) programme i.e. 'Mama Ye!' public engagement campaign [77]. The campaign is to create pressure on policymakers for their commitment and respond in prioritizing quality maternal and neonatal health services through digital media approaches [77]. The strategy could be relevant to the Nepalese context to create demand

of quality maternal health service and make service providers accountable toward their actions and responsibility, while people's preference for accessing health information and providing feedback is changing accordingly to the advancement of the technology in Nepal [22, 36, 64].

\section{Discussion}

The review found that Nepal is promising for improving the responsiveness of maternal health services. Different social accountability interventions have been implemented by government/state (supply-side) and development partners (demand-side) to improve the responsiveness of service providers and policymakers for quality maternal health services. The social audit, MPDSR, citizen charter and complaint/grievances handling interventions have been identified as supply-side interventions whereas the CSC and CHSB are identified as demand-side interventions. The health facility operation and management committee, FCHVs, and Mothers' group are found as a formal structure in the health system to ensure community engagement. They all are considered as part of the health system who bridge the community people and health facility as well as act as mediators to voice community concerns especially for the women, disadvantaged and marginalized groups in decision-making body. The HFOMC is inclusive in nature and represents the voices of different groups of people. The committee is more likely to generate the resources for quality services if they involve in the social accountability process. Likewise, improved women participation in social accountability interventions is directly associated with improved maternal and neonatal health outcomes [48]. Meanwhile, the CSOs are non-state structure and found to have an advocacy role for the social accountability interventions in maternal health services in the country.

The government has put effort through quotas system to ensure participation of women and disadvantaged groups in HFOMC [49] which is an appreciative step, but the quotas have only guaranteed the formal inclusions. It cannot ensure their meaningful participation in the decision-making process. Therefore, quota only is not adequate enough to empower people to voice their opinion and ensure their active participation in social accountability interventions [51, 58]. This review identified a gap in meaningful community participation in social accountability interventions. Mostly, the involvement of 
women and Dalit in the health facility committee and the decision-making process is often done as a formal procedure. Similarly, their level and depth of participation have not been ensured properly [22, 51, 58 , 64]. Meanwhile, the strong gender norms, caste discrimination, political and economic influences, resources deficiencies and weak enforceability mechanism found as most influencing factors for social accountability interventions in Nepal and this need to be considered while designing and implementing the interventions.

The social audit and MPDSR are widely promoted supply-side interventions in maternal health services in Nepal. The review showed that it has contributed to improving the responsiveness of Nepal's health system and the delivery of quality maternal health services. Despite its effectiveness, there is a gap identified in the quality implementation of the social audit which consequently affects its outcomes. This is due to contextual factors such as weak monitoring and regulatory mechanism in the health system, political interference, resource constraints in the health system and power limitation at the local level. It is evident that social audit has been practised in maternal health services as an event rather than a process. While researchers $[13,15,53]$ argue, social accountability as a continuous and regular process. In this situation, interventions may not produce expected outcomes. Similarly, it is also evident there is a lack of reflection on the processes and built action plans from lined authorities. Additionally, a gap identified in the integration of developed action plans during social audit into the policy level decision making [22, 24].

In relation to MPDSR, since it has been initiated long ago, no study has been done exploring its effectiveness or outcomes in maternal health in the context of Nepal. Therefore, further research is recommended to generate evidence. The MPDSR could be effective to improve the quality of maternal health services and avoid 'delays' in receiving the services if developed action plans are being implemented which has been evident from Bangladesh and Nigeria $[26,69]$.

Considering the difficulties of illiterate people who can't read the information written in citizen charter, it is necessary to ponder alternatives to make all them informed about the availability of services. Disseminating the information from television, radio and mobile phone can be the alternative means for these groups of people. In Nepal, almost every household has at least one mobile phone [55], which shows the opportunity of information dissemination via short message or voice message etc. Though the short message may not work for illiterate people again voice message or toll-free call services can be considered for them.

The review also identified a gap in the complaint capturing and handling mechanism in the health system. This is mainly due to lack of awareness, power asymmetry between providers and users and cultural barriers [22,64]. Mafuta, in his research [14] concluded the social accountability interventions work effectively in maternal health services if women are allowed to express their concerns and have channels to provide feedback, as well as health service providers, are positive toward user feedback and willing for behavioural changes [14] p.261. This applies to the context of Nepal as well where researches have already shown the relation between women participation in social accountability intervention and its impact on maternal health outcomes $[47,48]$. 
It is found that community people often prefer informal channels to express their complaint/grievances or provide feedback in Nepal. Eventually, the MOHP has already initiated a web-based complaint handling mechanism which is quite impressive [35]. However, this may not be feasible for the local population who are not internet users and technology-friendly meanwhile; they are a larger group in the country $[55,76]$. Therefore, the effort is needed to establish other informal channels like using committee members, mothers' group and anonymous complaint registry through call, etc. along with the formal channels otherwise relevant feedback or information could be missed out which needed to improve quality of maternal health services.

The political instability and bureaucracy influences have resulted in low trust among the community over the state, in such case, the government needs to put the effort in improving trust between citizen and state $[15,65]$. This will help to improve the client-provider relationships and effectiveness of social accountability interventions. To do so, it is very necessary to improve access to information for the community and increase their awareness of the right entitlements.

Without sufficient resources and power at the local level, social accountability cannot produce optimal outcomes. For example, studies have shown that fulfilment of the permanent post, constructing major infrastructures, drugs and commodities purchasing and improving monitoring and a supervisory visit from higher authorities in the health facilities etc. are not in the control of health management committee and community people $[22,24,36,58,70]$. Therefore, there is a need for proper devolution of power at a local level and strengthening the capacity of local government. This will further help to avoid political and economic interference and power symmetry as well as help to manage resource constraints at the local level.

Research suggests that for evidence to drive into action in maternal health services, it needs to be designed and communicate in a way that triggers the policymakers will to address persistent resource scarcity [77] which is found weak in Nepal. Therefore, the public campaign approach in sub-Saharan Africa described earlier [77] can be an effective strategy in the context of Nepal as well. This can be well done by CSOs as they are mostly in an advocacy role in the country.

Regarding demand-side interventions, the review found that they have proven to improve the quality of maternal health services in different LMICs like Nepal. Despite the effectiveness of improving health system responsiveness, some limitations have been observed. For example, the CHSB is focused on specific groups and project-oriented where sustainability largely depends upon the donors funding. Similarly, the MOHP was not able to scale-up CSC due to resource constraint and lack of technical competencies. The review found donor-initiated interventions have been implemented without a clear vision of its sustainability $[22,36]$. The CSC, CHSB and social audit have many similarities thus; implementation of fragmented interventions may lead to duplication of efforts and resource wastage. Therefore, the specific effort needed from both government and development partners for the integration of those interventions and in developing collaboration between them to improve efficiency and to ensure the sustainability of social accountability interventions. 


\section{Relevancy of the conceptual framework}

The conceptual framework is adapted from Lodenstein et al. was relevant for organizing and presenting the findings on social accountability interventions implemented in maternal health services in Nepal. It helped to analyse the community participation and influence of contextual factors in the social accountability interventions and also helped to link the outcomes in the maternal health services. Additionally, the original framework is developed reflecting on the context having weak governance capacity, therefore it was relevant to the context of Nepal. However, it didn't provide a clear insight into the processes or steps needed for the effective functioning of the social accountability interventions. Therefore, the model may not be relevant to perform the analysis of the processes/steps needed for the effective functioning of social accountability interventions.

\section{Limitations}

The findings are based on a literature review and desk study which explicitly depended on the availability of the literature and reports. Few studies were available to provide a comprehensive impression on the outcomes of social accountability interventions in the maternal health services in Nepal. This might due to the lack of studies or inclusion and exclusion criteria of the literature search strategy. Hence, studies from LMICs having similar maternal health and socio-economic context have been presented.

Furthermore, the analysis of the findings is only focused on quality issues in public health facilities, however, the private health institutions providing maternal health services have been also reported for poor QoC which have not been explored in this review $[7,9]$. The conclusions, therefore, should be comprehended and interpreted considering these limitations. However, this review has addressed quality issues by reviewing peer-reviewed articles, national-level survey reports and evaluation studies and evidence published in official governmental and organizational websites.

\section{Conclusions}

Various social accountability interventions have been implemented by supply and demand-side to improve the responsiveness of maternal health services in Nepal. Despite the effective outcomes of the supply-side interventions, quality implementation is a key issue. Insufficient monitoring and evaluation, resource constraints, weak respond ability in the health system and political influences are identified as major responsible factors for it. On the other hand, demand-side interventions also found to have positive influences on the health system responsiveness. However, the interventions are project-oriented and donor depended in Nepal. Therefore, clear policy guidance is needed for standardization and sustainability of the donor-initiated social accountability interventions. Similarly, the contextual factors such as socio-cultural factors: gender norms, social structure, value beliefs; health system factors: clientprovider relationship, resource availability, monitoring and evaluation, and political-economic factors are determining factor for effectiveness and sustainability of the social accountability interventions 
Social accountability interventions have the potential to increase health service providers' and policymakers' responsiveness toward improving the quality of maternal health services needed to reduce preventable maternal deaths in Nepal, however, contextual factors and quality implementation is needed to take into consideration. Moreover, there is a need for investment in research in social accountability interventions and its impact on maternal health services in the context of Nepal to enhance evidencebased practices.

\section{Abbreviations}

ANC

CARE

CHSB

CSC

CSO

DFID

DHO/DPHO

DOHS

E4A

EDPs

EmONC

FCHVs

GESI

HFOMC

HIV/AIDS

INGOS

LDO

LMICs

MDG antenatal care

Cooperative for Assistance and Relief Everywhere

Community Health Score Board

Community Score Card

Civil Society Organization

Department for International Development

District Health Office/District Public Health Office

Department of Health Services

Evidence for Action

external development partners

emergency obstetric and newborn care

Female Community Health Volunteers

gender equality and social inclusion

Health Facility Operation and Management Committee

Human Immunodeficiency Virus/Acquired Immunodeficiency Syndrome

International non-governmental organizations

Local Development Officer

low and middle-income countries

Millennium Development Goals 


\begin{tabular}{ll} 
MDR & Maternal Death Review \\
MMR & Maternal Mortality Ratio \\
MNH & maternal and neonatal health \\
MoFALD & Ministry of Federal Affairs and Local Development \\
MoHP & Ministry of Health/ Ministry of Health and Population \\
MPDSR & Maternal Perinatal Death Surveillance and Response \\
NHRC & Nepal Health Research Council \\
NHSS-IP & Nepal Health Sector Strategy-Implementation Plan \\
NHSSP & Nepal Health Sector Support Programme \\
OR & odds ratio \\
PHC & primary health care \\
PNC & postnatal Care \\
QoC & Quality of Care \\
RCT & randomized controlled trial \\
SBA & Skilled Birth Attendants \\
SDG & Sustainable Development Goal \\
USAID & United States Agency for International Development \\
WHO & World Health Organization \\
\hline
\end{tabular}

\section{Declarations}

Ethics approval and consent to participate

Not applicable

Consent for publication

Not applicable 


\section{Availability of data and materials}

Since this is rapid literature review, the PRISMA checklist is available and attached as supplementary materials

\section{Funding}

No fund was available for this rapid review

\section{Competing interests}

The authors declare that they have no competing interest

\section{Author's contributions}

AN, SKD and AvdK all have contributed to the concept of the study. All the authors were agreed for study methodology, conceptual framework and search strategy. AN and SKD searched and collected the literature and relevant reports. AN and SKD critically analysed the findings and drafted the manuscript. Critically revision of the manuscript for intellectual content was done by the AvdK. And SKD. All the authors were equally involved in the drafting, revision, and finalization of the manuscript. All the authors read and agreed for the final version of manuscript.

\section{Acknowledgment}

We acknowledge the guidance and supervision received from Anke van der Kwaak

\section{References}

1. World Health Organization (2015) Trends in Maternal Mortality: 1990 to 2015: estimates by WHO, UNICEF, UNFPA, World Bank Group and the United Nations Population Division. doi: ISBN 978924 1503631

2. Ministry of Health and Population (2007) Second Long Term Health Plan 1997-2017: Perspective Plan for Health Sector Development. Health Sector Reform Unit. Kathmandu

3. Ministry of Health and Population (2018) Annual Report 2073/74 (2016/17). Department of Health Services. Kathmandu

4. Ministry of Health and Population (2006) National Policy on Skilled Birth Attendants: Supplementary to Safe Motherhood Policy 1998. Family Health Division. Kathmandu 
5. Ministry of Health and Population (2014) Results from assessing birthing centers in Nepal. Family Health Division. Kathmandu

6. Ministry of Health Nepal, New ERA and, ICF (2017) Nepal Demographic and Health Survey 2016. Kathmandu, Nepal: Ministry of Health, Nepal.

7. Ministry of Health and Population (2015) Nepal Health Sector Strategy 2015-2020. NHSS. Kathmandu, Nepal

8. Ministry of Health and Population (MOHP) [Nepal], Health Research and Social Development Forum (HERD), Nepal Health Sector Support Program (NHSSP). 2014. (2014) Service Tracking Survey 2013. Kathmandu, Nepal: Ministry of Health and Population, HERD, and NHSSP, Ramsah Path, Kathmandu, Nepal

9. Ministry of Health (2016) Nepal's Every Newborn Action Plan. Department of Health Services. Kathmandu

10. Tunçalp Ö, Were W, MacLennan C, et al (2015) Quality of care for pregnant women and newborns-the WHO vision. BJOG An Int J Obstet Gynaecol 122:1045-1049

11. Hulton L, Matthews Z, Bandali S, Izge A, Daroda R, Stones W (2016) Accountability for quality of care: Monitoring all aspects of quality across a framework adapted for action. Int J Gynecol Obstet $132: 110-116$

12. Malena C, Forster R, Singh J (2004) Social accountability: an introduction to the concept and emerging practice. Social Development. The Wolrd Bank. Washington, DC

13. Malena C, Forster R, Singh J (2004) Social Accountability: An Introduction to the Concept and Emerging Practice. World Bank Social Development Papers: Participation and Civic EngagementWashington DC

14. Mafuta EM (2017) Improving performance and responsiveness of maternal health services through social accountability mechanisms in the Democratic Republic of the Congo: Strengthening the interface role in community participation. Vrije Universiteit Amsterdam

15. Lodenstein E, Dieleman M, Gerretsen B, Broerse JEW (2017) Health provider responsiveness to social accountability initiatives in low- and middle-income countries: A realist review. Health Policy Plan $32: 125-140$ 
16. Mafuta EM, Dieleman MA, Hogema LM, Khomba PN, Zioko FM, Kayembe PK, de Cock Buning T, Mambu TNM (2015) Social accountability for maternal health services in Muanda and Bolenge Health Zones, Democratic Republic of Congo: a situation analysis. BMC Health Serv Res 15:514

17. Lodenstein E, Dieleman M, Gerretsen B, Broerse JE (2013) A realist synthesis of the effect of social accountability interventions on health service providers' and policymakers' responsiveness. Syst Rev. doi: $10.1186 / 2046-4053-2-98$

18. World Health Organization (2016) Standards for improving quality of maternal and newborn care in health facilities. WHO. Geneva

19. The World Bank (2004) World development report 2004: Making services work for poor people. The World Bank and Oxford University Press. Washington, D.C.

20. de Silva A (2000) A framework for measuring responsiveness. EIP/GPE/EBD World Heal Organ 1-42

21. Hulton L, Matthews Z, Stones RW (2000) A framework for the evaluation of quality of care in maternity services. University of Southampton, Southampton

22. Jarman D, Ghimire K (2017) Situation Analysis on Social Accountability in the Health Sector (SAHS). DFID/Nepal Health Sector Programme III (NHSP3). Kathmandu

23. Neupane BD (2011) A review of social audit guidelines and practices in Nepal. Nepal Health Sector Support Programme. Kathmandu

24. Human Resource Development Center (2015) Social Audit Process Evaluation Report. Ministry of Health and Nepal Health Sector Support Programme. Kathmandu

25. van den Broek NR, Graham WJ (2009) Quality of care for maternal and newborn health: The neglected agenda. BJOG An Int J Obstet Gynaecol 116:18-21

26. Bandali S, Thomas C, Hukin E, Matthews Z, Mathai M, Ramachandran Dilip T, Roos N, Lawley R, Igado O, Hulton L (2016) Maternal Death Surveillance and Response Systems in driving accountability and influencing change. Int J Gynecol Obstet 135:365-371

27. Ministry of Health and Population (2015) Maternal and Perinatal Death Surveillance and Response (MPDSR) Guideline 2014. Family Health Division. Kathmandu

28. World Bank (2011) Social Accountability In Action. Program for Accountability in Nepal (PRAN). Kathmandu 
29. Kedar K, Chiranjibi B (2012) Sourcebook of 21 Social Accountability Tools. Program for Accountability in Nepal (PRAN), World Bank. Kathmandu

30. CARE-Nepal (2012) Community Health Score Board (CHSB). Strengthening Approaches for Maximizing Maternal, Neonatal and Reproductive Health (SAMMAN) Project. Kathmandu

31. Hamal M, Heiter K, Schoenmakers L, Smid M, de Cock Buning T, De Brouwere V, Bardají A, Nepal C, Dieleman M (2019) Social Accountability in Maternal Health Services in the Far-Western Development Region in Nepal: An Exploratory Study. Int J Heal Policy Manag 8:280-291

32. Tamang S, Malena C (2011) The Political Economy of Social Accountability in Nepal. Program for Accountability in Nepal (PRAN). Kathmandu

33. Nepal RB (2016) A study on the policies and practices of the Government of Nepal on the free distribution of medicine. Transparency International Nepal. Kathmandu

34. Ministry of Health and Population Feedback. In: Right to Information Act 2007. http://www.mohp.gov.np/feedbacks. Accessed 18 Dec 2018

35. Ministry of Health and Population (2017) Smart Health Nepal. In: Right to Information Act 2007. http://www.mohp.gov.np/. Accessed 15 Feb 2019

36. Pact (2017) Social Accountability in the Health Sector Programme (SAHS): Applied Political Economy Analysis (Baseline). U.K. Agency for International Development. Kathmandu

37. Ministry of Health, New ERA Nepal, Nepal Health Sector Support Program (NHSSP) and, ICF (2017) Nepal Health Facility Survey 2015. Kathmandu, Nepal:Ministry of Health, Nepal

38. Ministry of Health and Population (2019) Health facility operation and management committee-a reference guideline for local level.

39. Government of Nepal (2015) Constitution of Nepal, 2072 (2015). Ministry of Law, Justice and Parliamentary Affairs, Kathmandu, Nepal

40. Oostdam S, Hamal M, Dieleman M, De Brouwere V, Bardají A, Tiwari DP, de Cock Buning T (2019) Social accountability in maternal health services in Baglung district, Nepal: a qualitative study. $J$ Glob Heal Reports. doi: 10.29392/joghr.2.e2018041

41. Ministry of Health and Population (2014) Success factors for women's and children's health: Nepal. doi: ISBN 9789241509046 
42. Shakya HS, Adhikari S, Gurung G, Pant S, Aryal S, Singh A, Sherpa MG (2012) Strengthening national health systems for improving efficiency of health service delivery in Nepal. J Nepal Health Res Counc 10:101-7

43. CARE (2011) Governance and Health Case Study: Linking Governance and Empowerment to Improved Maternal and Newborn Health Services in Nepal. Atlanta

44. Ministry of Health and Population (2010) National Female Community Health Volunteer Program Strategy (Unofficial Translation). Family Health Division. Kathmandu

45. Khatri RB, Mishra SR, Khanal V (2017) Female Community Health Volunteers in Community-Based Health Programs of Nepal: Future Perspective. Front Public Heal 5:1-4

46. Hamal M, Dieleman M, De Brouwere V, de Cock Buning T (2018) How do accountability problems lead to maternal health inequities? A review of qualitative literature from Indian public sector. Public Health Rev 39:9

47. Manandhar D, Osrin D, Shrestha B, et al (2004) Effect of a participatory intervention with women's group on birth outcomes in Nepal: cluster randomized controlled trial. Lancet 364:970-979

48. Prost A, Colbourn T, Seward N, et al (2013) Women's groups practising participatory learning and action to improve maternal and newborn health in low-resource settings: a systematic review and meta-analysis. Lancet 381:1736-1746

49. Ministry of Federal Affairs and Local Development (2017) Annual Progress Report- NFY 2073/74 (2016/2017). Local Governance and Community Development Programme (LGCDP)-II. Kathmandu

50. Ministry of Health (2017) Nepal Health Sector Strategy - Implementation Plan 2016-2021. NHSS. Kathmandu

51. Cima O (2013) Accountability at the Local Level in Fragile Contexts: Nepal Case Study.

52. National Planning Commission Secretariat (2015) Nepal in Figures 2015. Central Bureau of Statistics. Kathmandu

53. Rifkin SB (2014) Examining the links between community participation and health outcomes: A review of the literature. Health Policy Plan 29:98-106

54. National Planning Commission Secretariat (2012) National population and housing census 2011 (National report). Central Bureau of Statistics. Kathmandu 
55. Ministry of Health Nepal, New ERA and, ICF (2017) Nepal Demographic and Health Survey 2016. Kathmandu, Nepal. Ministry of Health, Nepal

56. Ministry of Health and Population (2013) Human Resources for Health Nepal Country Profile. Nepal Health Sector Support Programme. Kathmandu

57. Paudel NR (2016) Inclusive policy implementation in Nepal: A case study of civil service. South Asian J Soc Sci 1-18

58. Gurung G, Derrett S, Hill PC, Gauld R (2018) Nepal's Health Facility Operation and Management Committees: exploring community participation and influence in the Dang district's primary care clinics. Prim Health Care Res Dev 1-11

59. Ghale S (2018) The long, hard road to federalism: A new report reveals the challenges that local governments are facing across the country. Kathmandu Post

60. Fehringer J, Bhandari P, Ghimire D, Lohani JR, Dawadi B, Acharya V, Adhikari B (2015) Impact evaluation of approaches to strengthen health facility operation and management committees in Nepal. Summary of the baseline report. MEASURE Evaluation. North Carolina

61. Gurung G, Gauld R, Hill PC, Derrett S (2018) Citizen's Charter in a primary health-care setting of Nepal: An accountability tool or a "mere wall poster"? Heal Expect 21:149-158

62. McCoy DC, Hall JA, Ridge M (2012) A systematic review of the literature for evidence on health facility committees in low- and middle-income countries. Health Policy Plan 27:449-466

63. Hoffmann KD (2014) The Role of Social Accountability in Improving Health Outcomes: Overview and Analysis of Selected International NGO Experiences to Advance the Field. Washington, DC: CORE Group

64. Gurung G, Derrett S, Gauld R, Hill PC (2017) Why service users do not complain or have 'voice': a mixed-methods study from Nepal's rural primary health care system. BMC Health Serv Res 17:81

65. Gurung G, Derrett S, Hill PC, Gauld R (2016) Governance challenges in the Nepalese primary health care system: time to focus on greater community engagement? Int J Health Plann Manage 31:167174

66. Harris D, Wales J, Jones H, Rana T, Chitrakar LR (2013) Human resources for health in Nepal. The politics of access in remote areas. Overseas Development Institute. London 
67. Dixit K (2018) Red Rice. Nepali Times

68. Federal Ministry for Economic Cooperation and Development (2015) Making local health services accountable: Social auditing in Nepal's health sector. GIZ (Deutsche Gesellschaft für Internationale Zusammenarbeit). Germany

69. Biswas A, Rahman F, Halim A, Eriksson C, Dalal K (2014) Maternal and Neonatal Death Review (MNDR): A Useful Approach to Identifying Appropriate and Effective Maternal and Neonatal Health Initiatives in Bangladesh. Health (Irvine Calif) 6:1669-1679

70. Gullo S, Galavotti C, Sebert Kuhlmann A, Msiska T, Hastings P, Marti CN (2017) Effects of a social accountability approach, CARE's Community Score Card, on reproductive health-related outcomes in Malawi: A cluster-randomized controlled evaluation. PLoS One 12:e0171316

71. Blake C, Annorbah-Sarpei NA, Bailey C, Ismaila Y, Deganus S, Bosomprah S, Galli F, Clark S (2016) Scorecards and social accountability for improved maternal and newborn health services: A pilot in the Ashanti and Volta regions of Ghana. Int J Gynecol Obstet 135:372-379

72. Schaaf M, Topp SM, Ngulube M (2017) From favours to entitlements: community voice and action and health service quality in Zambia. Health Policy Plan 32:847-859

73. Atela M, Bakibinga P, Ettarh R, Kyobutungi C, Cohn S (2015) Strengthening health system governance using health facility service charters: A mixed methods assessment of community experiences and perceptions in a district in Kenya. BMC Health Serv Res 15:539

74. Commission for the Investigation of Abuse of Authority (2018) 28th CIAA Annual Report. CIAA. Kathmandu

75. Mafuta EM, De Cock Buning T, Lolobi DL, Mayala PM, Mambu TNM, Kayembe PK, Dieleman MA (2018) Factors influencing the capacity of women to voice their concerns about maternal health services in the Muanda and Bolenge Health Zones, Democratic Republic of the Congo: a multimethod study. BMC Health Serv Res. doi: 10.1186/s12913-018-2842-2

76. International Telecommunications Union (ITU) (2016) Percentage of individuals using the internet. Ctry. ICT Data

77. Hulton L, Matthews Z, Martin-Hilber A, Adanu R, Ferla C, Getachew A, Makwenda C, Segun B, Yilla M (2014) Using evidence to drive action: A "revolution in accountability" to implement quality care for better maternal and newborn health in Africa. Int J Gynecol Obstet 127:96-101 
Figures

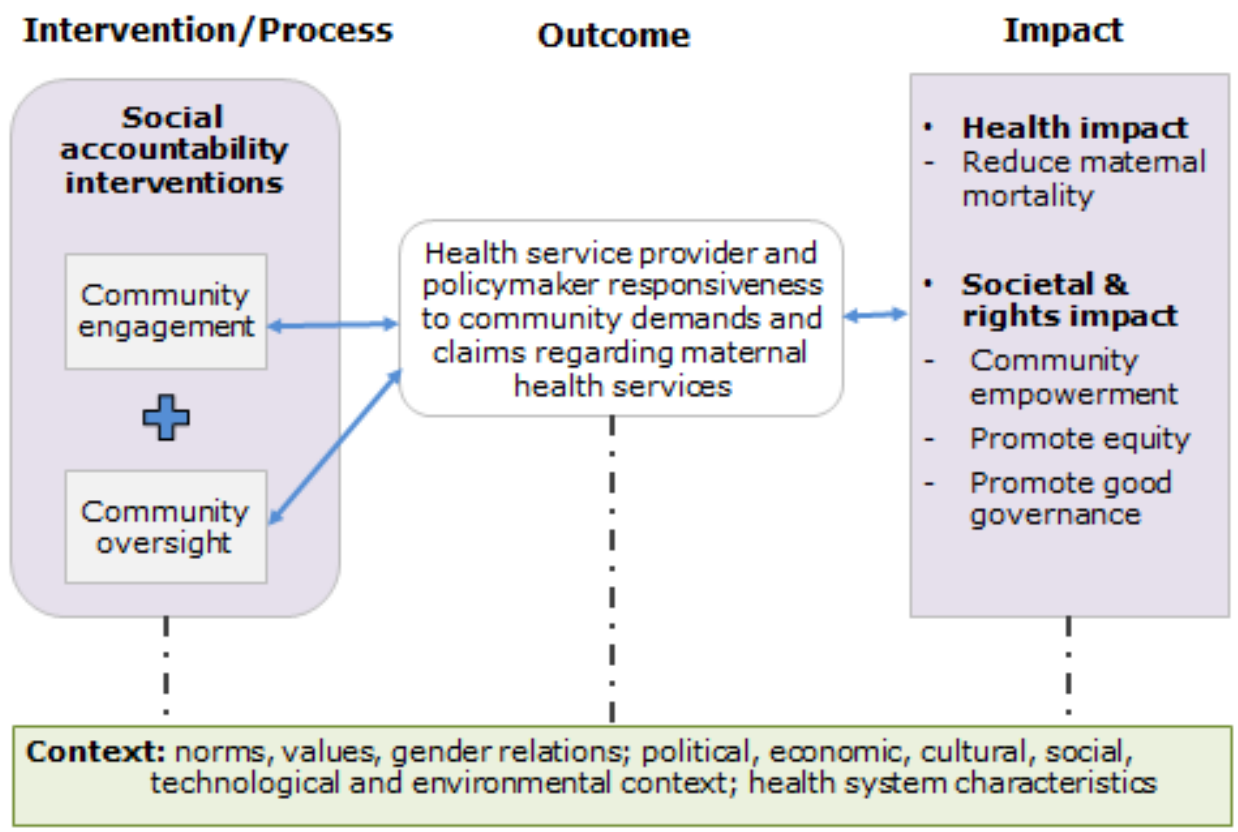

\section{Figure 1}

Conceptual framework on social accountability adapted from Lodenstein et al., 2013 [17]. 


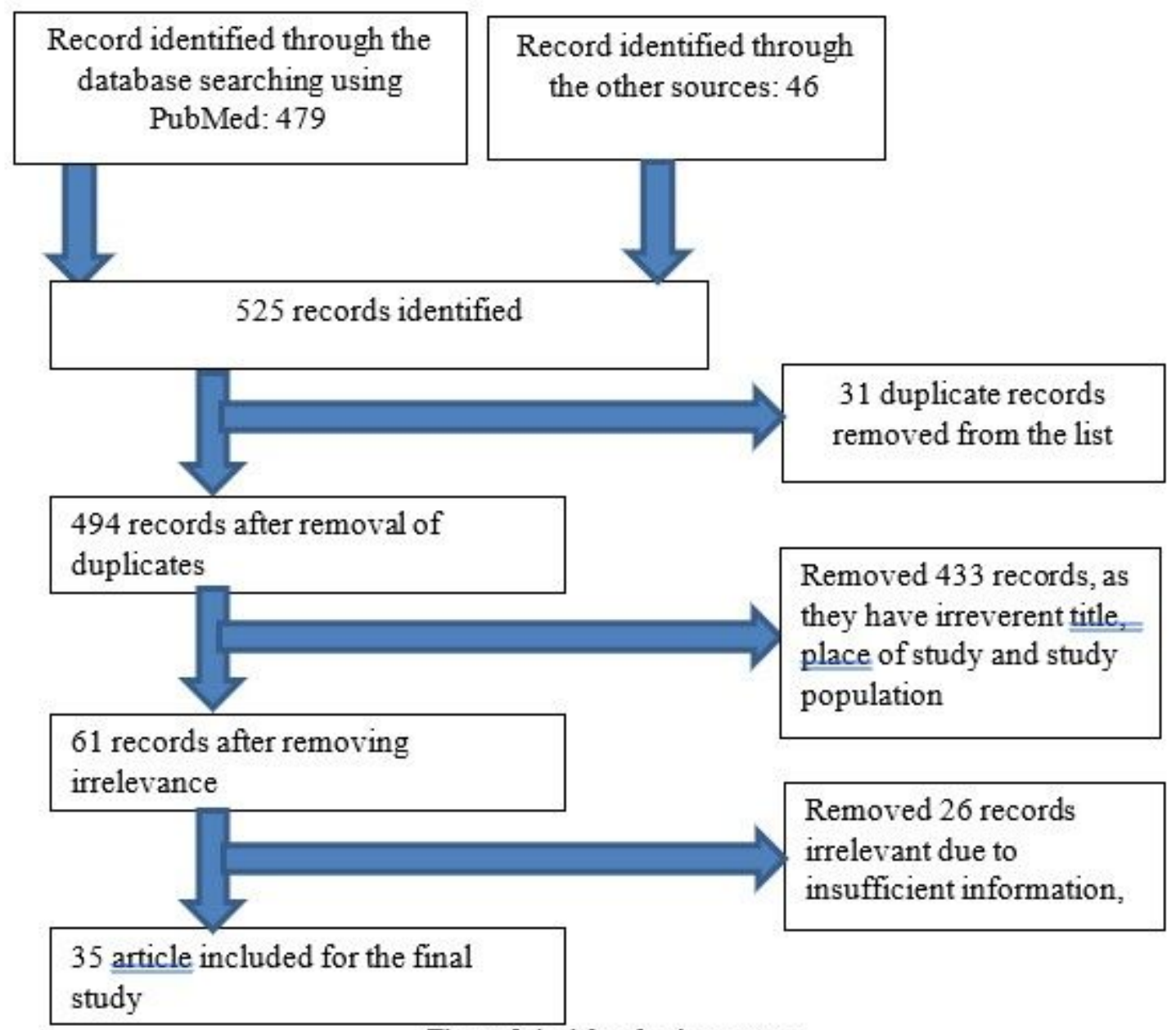

Figure 2 Article selection process

\section{Figure 2}

Article selection process. 


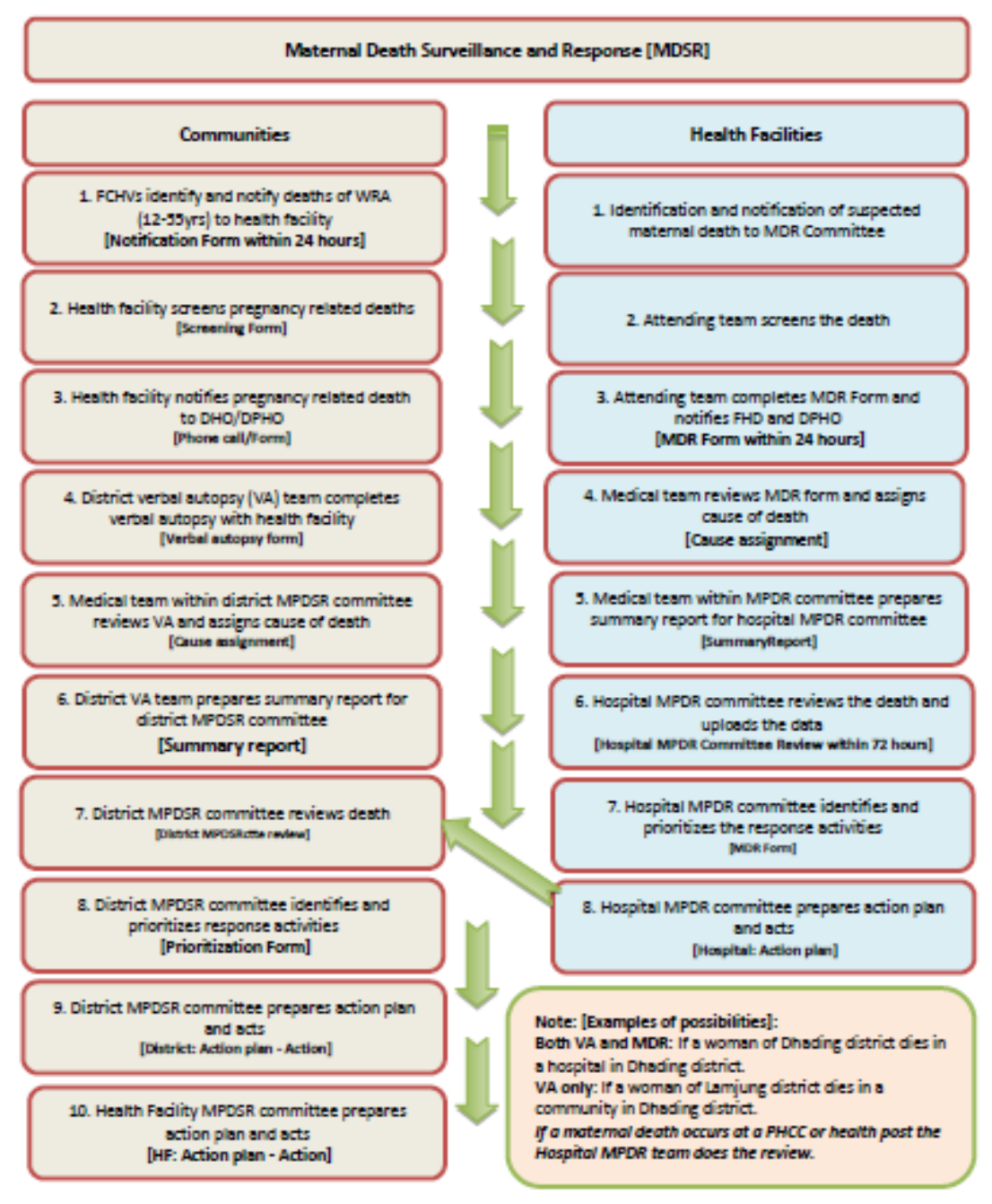

\section{Figure 3}

Process of MPDSR at community and health facility level [3].

\section{Supplementary Files}

This is a list of supplementary files associated with this preprint. Click to download.

- PRISMA2009checklist.doc 